\title{
COMPARACIONES FLORÍSTICAS Y FAUNÍSTICAS ENTRE DIFERENTES LUGARES DE BOSQUES DE TIERRA FIRME EN LA SELVA BAJA DE LA AMAZONÍA PERUANA
}

Juan José Rodríguez Gamarra ${ }^{1}$, Glenda G. Cárdenas Ramírez ${ }^{1}$, Alicia De La Cruz Abarcaํㅜ, Nelly Llerena Martínez ${ }^{1}$, Sandra Ríos Torres ${ }^{1}$, Carlos Rivera Gonzáles ${ }^{1}$, Edwin Salazar Zapata ${ }^{1}$, Víctor Hugo Vargas Paredes ${ }^{1}$, Pekka Soini $^{2}$ y Kalle Ruokolainen ${ }^{3}$

\section{RESUMEN}

Se investigaron patrones de similitudes y diferencias florísticas y faunísticas entre áreas en cinco zonas de la selva baja peruana (Andoas, Iquitos, Pampa Hermosa, Iñapari y Tambopata), utilizando tres grupos de plantas (helechos, melastomatáceas y palmeras), y tres grupos de animales (aves, anuros y hormigas) como especies indicadoras de las composiciones florísticas y faunísticas locales. El estudio se realizó en el marco del proyecto Diversidad Biológica de la Amazonía Peruana, Perú - Finlandia (BIODAMAZ). La riqueza de especies de plantas varió marcadamente entre zonas, siendo Andoas la zona de mayor riqueza de especies para todos los grupos de plantas, posiblemente debido a la presencia en el área de suelos con material volcánico. Se evidenció un patrón común de similitudes florísticas entre zonas y este patrón no tenía relación con las distancias geográficas entre las zonas. Los grupos de animales no mostraron ningún patrón común de similitudes y diferencias faunísticas entre las localidades de inventario. Las composiciones faunísticas locales de los grupos de animales no mostraron correlaciones significativas, ni con las características edáficas, como tampoco con las composiciones florísticas correspondientes de árboles y palmeras. En contraste con esto, la composición florística de palmeras estuvo altamente correlacionada con la composición de árboles y débilmente correlacionada con las características edáficas. La comparación de las composiciones florísticas locales con los correspondientes valores de reflectancia en la imagen de satélite indicó la existencia de una buena correlación positiva entre éstos. Los resultados arriba mencionados indican que los tres grupos de plantas utilizados en este estudio son buenos indicadores de las características ambientales (suelo), y por ende pueden ser utilizados como indicadores de los patrones florísticos generales, mientras que los grupos de animales utilizados no lo son.

Palabras clave: Anuros, aves, especies indicadoras, helechos, hormigas, Melastomataceae, palmeras, patrones de distribución, Perú, riqueza de especies, selva baja amazónica.

\footnotetext{
ABSTRACT

Patterns of floristic and faunistic similarities and differences between areas in five areas of the Peruvian tropical lowland forest (Andoas, Iquitos, Pampa Hermosa, Iñapari and Tambopata) were investigated. Three groups of plants (ferns, palms and Melostamataceae) and three groups of animals (birds, anuran frogs and ants) were used as indicator species of the local floristic and faunistic composition. The study was carried out as part of the Peru-Finland Peruvian Amazon Biological Diversity project (BIODAMAZ). The richness of plant species varied markedly between these areas, with Andoas showing the highest species richness out of all the plants, possibly due to the presence of volcanic material in the soil of the area. A common pattern of floristic similarities was evident between areas, but the pattern did not bear any relationship to the geographic distances between the areas. The animal groups showed no common pattern of faunal similarities and differences between inventory locations. The local faunistic composition of the animal groups showed no significant correlation, not in soil characteristics nor corresponding floristic compositions of trees or palms. In contrast, the floristic composition

1 Proyecto Diversidad Biológica de la Amazonía Peruana - BIODAMAZ, Perú - Finlandia. Av. Abelardo Quiñones km 2.5, Iquitos, Perú. Correo electrónico: biodamaz@iiap.org.pe

2 Proyecto Diversidad Biológica de la Amazonía Peruana - BIODAMAZ, Perú - Finlandia. Av. Abelardo Quiñones km 2.5, Iquitos, Perú / Programa de Investigación para el Aprovechamiento Sostenible de la Biodiversidad - PBIO, Instituto de Investigaciones de la Amazonía Peruana - IIAP, Av. Abelardo Quiñones km 2.5, Iquitos, Perú. Correo electrónico: biodamaz@iiap.org.pe

3 Proyecto Diversidad Biológica de la Amazonía Peruana - BIODAMAZ, Perú - Finlandia, Av. Abelardo Quiñones km 2.5, Iquitos, Perú / Departamento de Biología, Universidad de Turku, 20014 Turku, Finlandia. Correo electrónico: biodamaz@iiap.org.pe
} 
of palms was highly correlated with the composition of trees and weakly correlated with the soil characteristics. A comparison of local floristic compositions of ferns with corresponding satellite image reflectance values showed that these were positively correlated. The results reported above suggest that all three plant groups used in this study are good indicators of environmental (soil) characteristics and can thus be used as indicators of general floristic patterns, whereas the animal groups used are not.

Key words: Amazonian lowland, ants, anuran frogs, birds, ferns, indicator species, Melastomataceae, palms, Peru, species distribution patterns, species richness.

\section{INTRODUCCIÓN}

La visión general que se tiene de los bosques amazónicos es de bosques exuberantes, con árboles de gran tamaño (hasta mayores de 30-40 metros) cargados de lianas, epífitas y asociados con cientos de especies de otras plantas. Pero, en una escala más detallada se puede observar la existencia de una gran variación, tanto en la estructura como en la composición florística entre bosques de diferentes lugares (Ruokolainen y Tuomisto, 1998). El conocimiento de la distribución geográfica de las especies es un componente importante para la comprensión de los procesos biológicos de la Amazonía (Tuomisto y Ruokolainen, 1998). Para manejar y conservar de una manera inteligente y sostenible dicha región es urgente conocer mejor los patrones de distribución de las especies de flora y fauna.

En la práctica es imposible estudiar la distribución geográfica de todas las especies amazónicas en el campo, debido a los problemas logísticos que representan la riqueza extrema de especies, y la taxonomía no resuelta de su flora (Ruokolainen et al., 1997). Sin embargo, podemos concentrar los esfuerzos en determinados grupos de organismos -especies indicadoras-, que pueden darnos información suficiente de las características ambientales de los lugares donde otras especies ocurren (Ruokolainen et al., 1994; 1997; Vormisto et al., 2000). El muestreo puede ser reducido significativamente, si es que existieran asociaciones entre diferentes grupos de plantas y animales, es decir, si existieran indicadores de los patrones generales de la distribución de especies.

En el proyecto Diversidad Biológica de la Amazonía Peruana, Perú - Finlandia (BIODAMAZ) ${ }^{4}$, fueron seleccionados seis grupos de especies para un estudio de campo, con el objeto de determinar si existen dichas asociaciones entre los organismos, y entre éstos y las características ambientales. Los grupos estudiados fueron: las plantas de la familia Melastomataceae, pteridófitas (helechos) terrestres, palmeras, las hormigas de la tribu Dacetini, los anfibios anuros de las familias Dentrobatidae, Hylidae y Leptodactylidae, y las aves.

En cuanto a la flora, tanto las melastomatáceas como las pteridófitas son consideradas como buenos indicadores del tipo de hábitat o de la calidad del suelo, porque cumplen con varios criterios para ser considerados como tales. Lo más importante es que reflejan bien los patrones de distribución de especies de otros grupos de plantas, como árboles y palmeras (Ruokolainen et al., 1997; Ruokolainen y Tuomisto, 1998; Vormisto el al., 2000). Además, son plantas de tamaño relativamente pequeño, lo que permite su fácil observación y colección; son fáciles de reconocer en el bosque; tienen suficientes especies, presentando una amplia variación de adaptaciones ecológicas, pero sin ser tantas como para hacer difícil su identificación en el campo; son relativamente bien conocidas taxonómicamente (pteridófitas) o tienen características (pelos, forma de venación), que permiten diferenciar las especies aunque no tengan flores o frutos (melastomatáceas); son comunes en bosques de diferentes tipos; y no son utilizadas por el hombre por lo que su distribución es poco afectada por las actividades antropogénicas (Tuomisto y Ruokolainen, 1998). Las palmeras tienen también varias de estas características, incluyendo la correlación con los patrones de distribución de otros grupos de plantas (Vormisto, 2000), aunque no son tan fáciles de colectar e identificar; además, muchas especies son utilizadas por el hombre.

En contraste con los grupos de plantas, no hay estudios previos de posibles correlaciones entre los patrones de distribución de especies de animales con otros grupos de animales o con plantas. Por eso, la selección de grupos de animales con los cuales se trabajó en el proyecto BIODAMAZ se basó en consideraciones que tomaron en

4 Proyecto Diversidad Biológica de la Amazonía Peruana (BIODAMAZ) es un convenio entre los gobiernos del Perú y de Finlandia ejecutado conjuntamente por el Instituto de Investigaciones de la Amazonía Peruana (IIAP) y por el consorcio finlandés formado por la empresa de consultorías ambientales, Biota BD Oy, y por la Universidad de Turku. 


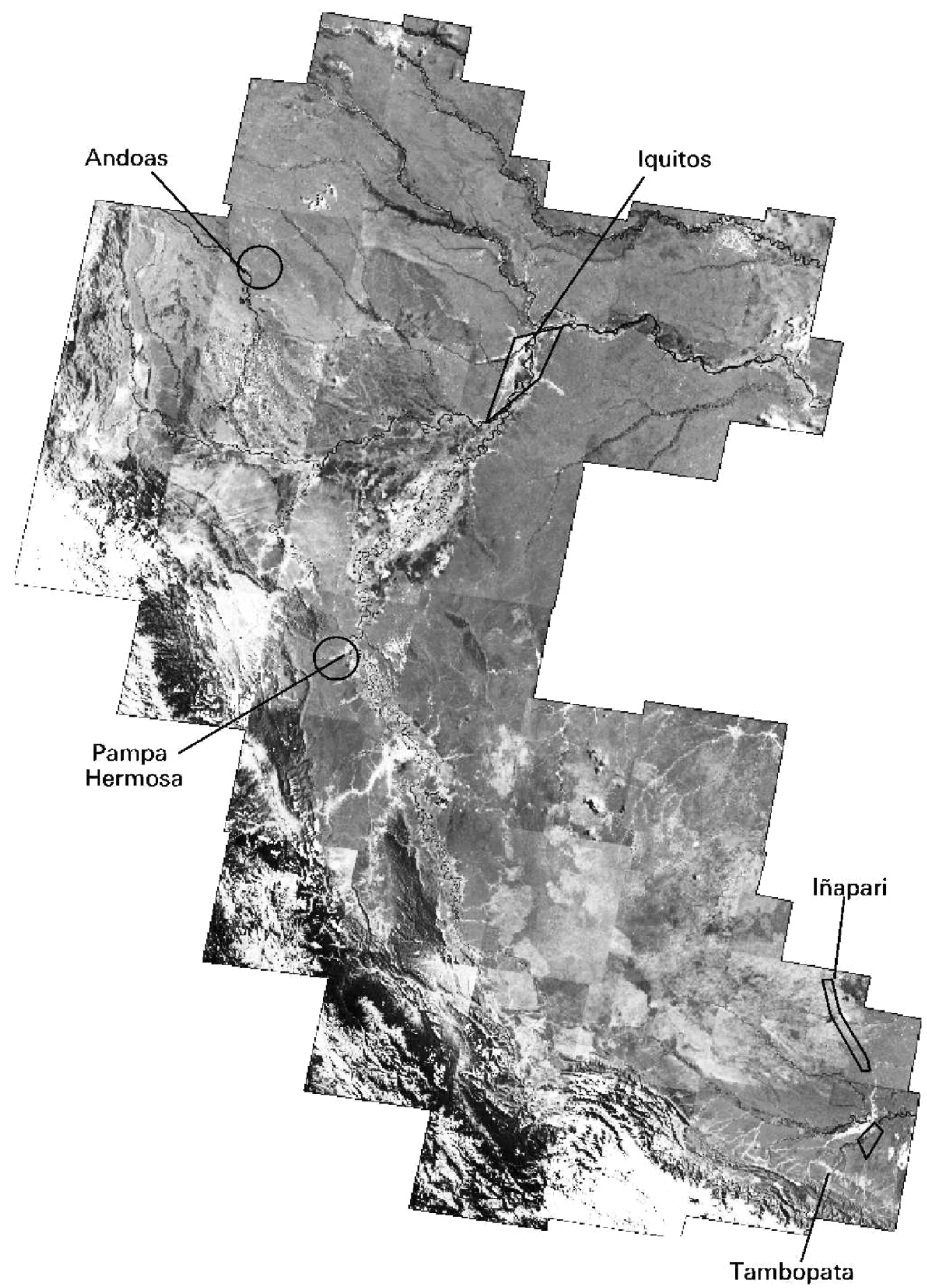

Figura 1. Mosaico de imágenes de satélite de la selva baja peruana indicando las zonas de muestreo. 
cuenta las posibilidades técnicas y metodológicas de trabajar más ampliamente con especies indicadoras, en el caso de que los estudios de correlación entre los patrones de distribución tuvieran resultados positivos.

Para los grupos de fauna, las hormigas son candidatas buenas para ser utilizadas como un grupo indicador porque tienen muchas especies, se encuentran abundantemente en todos los hábitats terrestres, y son fáciles de colectar (Majer, 1983). Son particularmente apropiadas para programas de inventarios y monitoreo debido a que la mayoría de las especies son sedentarias, y construyen nidos perennes con áreas restringidas de forrajeo. Por eso -en contraste con otros insectos que se mueven frecuentemente entre hábitats en busca de alimento, pareja o sitios para anidar-, las hormigas están mayormente presentes en un sitio y pueden ser fácilmente muestreadas y monitoreadas (Alonso, 2000).

Los anuros podrían ser utilizados como indicadores de patrones de distribución de otras especies amazónicas porque tienen un número cómodo de especies, no demasiado grande ni muy pequeño. También se conoce que existen varias especies que son especialistas de hábitats (Heyer et al., 1994). Además, recientemente se ha generado bastante interés sobre los anuros por los informes de que sus poblaciones están disminuyendo en muchas partes de la tierra. Debido a este interés, hay muchos taxónomos y ecólogos trabajando con anuros, lo que significa que hay más oportunidades de encontrar ayuda y colaboración. Por otra parte, los anuros tienen la desventaja de que la mayoría de las especies están activas principalmente durante períodos específicos del año, y solamente bajo ciertas condiciones climáticas. Esta característica definitivamente dificulta los inventarios de los anuros.

Las aves pueden ser consideradas como un buen grupo potencial para indicadores de patrones de distribución de otras especies. Existen especies especialistas de determinados hábitats, como también especies endémicas y especies de distribución muy restringida. Tal vez lo más importante es que las aves son taxonómicamente muy bien conocidas, lo que significa que hay una mínima necesidad de hacer colectas, que siempre atrasan el avance del trabajo de inventario. Además, las aves interesan a mucha gente y por eso un estudio de ellas, en comparación con otros grupos menos carismáticos, siempre va a llamar la atención, atraer más fondos, e impactar más a la gente que toma las decisiones sobre conservación y uso.

En el presente estudio investigamos los patrones de distribución y abundancia de las especies de los grupos seleccionados como indicadores en la región de la selva baja de la Amazonía peruana, mediante inventarios de estas especies en cinco zonas geográficamente distantes entre sí (Figura 1 y Cuadro 1). También investigamos la relación entre la composición florística de uno de los grupos indicadores y el área basal del bosque. En una escala más local, en la sub-región de Andoas - Iquitos investigamos, además, la relación entre la distribución de las especies indicadoras y las características del suelo. Asimismo, realizamos una comparación del patrón de distribución de los helechos con los patrones de reflectancia (manchas de diferentes colores) en las imágenes de satélite.

Con estos estudios pretendemos evaluar la utilidad de los grupos indicadores seleccionados y contribuir con información valiosa para definir, por ejemplo, áreas prioritarias para la conservación, al entender de qué manera se distribuyen las especies y así poder predecir lugares con asociaciones vegetales y animales particulares. Así, al observar una imagen de satélite en la que aparecen diversos colores, podrémos estimar hasta qué punto la variación en los colores refleja variación en la composición de especies.

Cuadro 1. Distancias aproximadas entre las cinco zonas de estudio.

\begin{tabular}{lll}
\hline De & A & Km (Aprox.) \\
\hline Iquitos & Andoas & 370 \\
Iquitos & Pampa Hermosa & 445 \\
Iquitos & Iñapari & 900 \\
Iquitos & Tambopata & 1120 \\
Andoas & Pampa Hermosa & 505 \\
Andoas & Iñapari & 1180 \\
Andoas & Tambopata & 1370 \\
Pampa Hermosa & Iñapari & 750 \\
Pampa Hermosa & Tambopata & 905 \\
Tambopata & Iñapari & 245 \\
\hline
\end{tabular}




\section{MATERIAL Y MÉTODO}

\subsection{Descripción de las zonas de muestreo}

Debido a la información ya existente sobre la distribución de árboles, melastomatáceas, helechos y análisis de suelos en la zona de Iquitos (Ruokolainen y Tuomisto, 1998), establecimos nueve transectos de 500 x 5 m en ocho lugares de bosques de tierra firme donde ya existía dicha información, para registrar la presencia y abundancia de las palmeras, anuros, hormigas y aves.

Otras zonas inventariadas fueron Andoas, con 11 transectos de inventarios para melastomatáceas, helechos y palmeras y uno para aves, hormigas y anuros; Pampa Hermosa, con 8 transectos para los tres grupos de plantas; Iñapari (carretera Puerto Maldonado-Iñapari), con 10 transectos para los tres grupos de plantas más un transecto para cada uno de los grupos de animales; y Tambopata, con 9 transectos para los tres grupos de plantas (Cuadro 2). Para la zona de Iñapari, el inventario de anuros no fue adecuado debido a desfavorables condiciones ambientales (época extremadamente seca), y los resultados del inventario de hormigas está pendiente de la identificación taxonómica de los espécimenes colectados, por lo que los grupos indicadores zoológicos no fueron incluidos en el análisis comparativo de patrones de similitudes y diferencias a nivel de la macroregión (para el listado de aves registradas en Iñapari, ver Anexo 4).

Cuadro 2. Ubicación de los transectos de inventarios en las cinco zonas de muestreo.

\begin{tabular}{|c|c|c|c|c|c|c|c|c|c|}
\hline \multicolumn{10}{|c|}{ Zona de Andoas } \\
\hline Transecto & Ubicación & Coordenadas & Orientación & Melastomatáceas & Helechos & Palmeras & Hormigas & Anuros & Aves \\
\hline 1 & $\begin{array}{l}\text { Carretera Andoas - } \\
\text { Huayurí km } 13\end{array}$ & $\begin{array}{l}02^{\circ} 45.169^{\prime} \mathrm{S} \\
76^{\circ} 26.278^{\prime} \mathrm{O}\end{array}$ & $340^{\circ}$ & $\mathrm{x}$ & $\mathrm{x}$ & $\mathrm{x}$ & $\mathrm{x}$ & $\mathrm{x}$ & $\mathrm{x}$ \\
\hline 2 & $\begin{array}{l}\text { Carretera Andoas - } \\
\text { Huayurí km } 22\end{array}$ & $\begin{array}{l}02^{\circ} 44.468^{\prime} \mathrm{S} \\
76^{\circ} 23.815^{\prime} \mathrm{O}\end{array}$ & $170^{\circ}$ & $\mathrm{X}$ & $\mathrm{X}$ & $\mathrm{X}$ & & & \\
\hline 3 & $\begin{array}{l}\text { Carretera Andoas - } \\
\text { Huayurí km } 26\end{array}$ & $\begin{array}{l}02^{\circ} 44.349^{\prime} \mathrm{S} \\
76^{\circ} 21.949^{\prime} \mathrm{O}\end{array}$ & $320^{\circ}$ & $\mathrm{x}$ & $\mathrm{X}$ & $\mathrm{X}$ & & & \\
\hline 4 & $\begin{array}{l}\text { Carretera Andoas - } \\
\text { Huayurí km } 29\end{array}$ & $\begin{array}{l}02^{\circ} 43.512^{\prime} \mathrm{S} \\
76^{\circ} 21.257^{\prime} \mathrm{O}\end{array}$ & $340^{\circ}$ & $\mathrm{x}$ & $\mathrm{x}$ & $\mathrm{x}$ & & & \\
\hline 5 & $\begin{array}{l}\text { Margen derecha } \\
\text { río Pastaza }\end{array}$ & $\begin{array}{c}02^{\circ} 48.966^{\prime} \mathrm{S} \\
76^{\circ} 28.860\end{array}$ & $210^{\circ}$ & $\mathrm{x}$ & $\mathrm{x}$ & $\mathrm{x}$ & & & \\
\hline 6 & $\begin{array}{l}\text { Carretera Andoas - } \\
\text { Huayurí km } 30\end{array}$ & $\begin{array}{l}02^{\circ} 42.317^{\prime} \mathrm{S} \\
76^{\circ} 20.389^{\prime} \mathrm{O}\end{array}$ & $290^{\circ}$ & $\mathrm{x}$ & $\mathrm{x}$ & $\mathrm{x}$ & & & \\
\hline 7 & $\begin{array}{l}\text { Carretera Andoas - } \\
\text { Huayurí km } 36\end{array}$ & $\begin{array}{l}02^{\circ} 41.505^{\prime} \mathrm{S} \\
76^{\circ} 18.928^{\prime} \mathrm{O}\end{array}$ & $90^{\circ}$ & $\mathrm{x}$ & $\mathrm{x}$ & $\mathrm{x}$ & & & \\
\hline 8 & $\begin{array}{l}\text { Carretera Tambo } \\
\mathrm{km} 2\end{array}$ & $\begin{array}{l}02^{\circ} 49.177^{\prime} \mathrm{S} \\
76^{\circ} 24.694^{\prime} \mathrm{O}\end{array}$ & $140^{\circ}$ & $\mathrm{x}$ & $\mathrm{x}$ & $\mathrm{x}$ & & & \\
\hline 9 & $\begin{array}{l}\text { Carretera Andoas - } \\
\text { Huayurí km } 46\end{array}$ & $\begin{array}{l}02^{\circ} 37.909^{\prime} \mathrm{S} \\
76^{\circ} 15.853^{\prime} \mathrm{O}\end{array}$ & $310^{\circ}$ & $\mathrm{x}$ & $\mathrm{x}$ & $\mathrm{x}$ & & & \\
\hline 10 & $\begin{array}{l}\text { Margen derecha } \\
\text { río Pastaza. }\end{array}$ & $\begin{array}{l}02^{\circ} 47.031^{\prime} \mathrm{S} \\
76^{\circ} 33.258^{\prime} \mathrm{O}\end{array}$ & $250^{\circ}$ & $\mathrm{x}$ & $\mathrm{x}$ & $\mathrm{x}$ & & & \\
\hline 11 & $\begin{array}{l}\text { Carretera Capahuari } \\
\text { Norte } \mathrm{km} 20\end{array}$ & $\begin{array}{l}02^{\circ} 40.427^{\prime} \mathrm{S} \\
76^{\circ} 29.883^{\prime} \mathrm{O}\end{array}$ & $130^{\circ}$ & $\mathrm{x}$ & $\mathrm{x}$ & $\mathrm{x}$ & & & \\
\hline
\end{tabular}


JUAN JOSÉ RODRÍGUEZ GAMARRA, GLENDA G. CÁRDENAS RAMÍREZ, ALICIA DE LA CRUZ ABARCA,

\begin{tabular}{|c|c|c|c|c|c|c|c|c|c|}
\hline \multicolumn{10}{|c|}{ Zona de Iquitos } \\
\hline Transecto & Ubicación & Coordenadas & Orientación & Melastomatáceas & Helechos & Palmeras & Hormigas & Anuros & Aves \\
\hline 1 & $\begin{array}{l}\text { Carretera Nauta-Iquitos } \\
\text { (Nauta) km } 9.5\end{array}$ & $\begin{array}{l}04^{\circ} 26.73^{\prime}, \mathrm{S} \\
73^{\circ} 35.15^{\prime} \mathrm{O}\end{array}$ & $180^{\circ}$ & & & $\mathrm{X}$ & $\mathrm{x}$ & $\mathrm{x}$ & $\mathrm{x}$ \\
\hline 2 & $\begin{array}{l}\text { Comunidad de } \\
\text { Gengen, río Momón }\end{array}$ & $\begin{array}{l}03^{\circ} 36.52, \mathrm{~S} \\
73^{\circ} 17.59^{\prime} \mathrm{O}\end{array}$ & $90^{\circ}$ & & & $\mathrm{x}$ & $\mathrm{x}$ & $\mathrm{x}$ & $\mathrm{x}$ \\
\hline 3 & $\begin{array}{l}\text { Comunidad de } \\
\text { Tarapota, rìo Nanay }\end{array}$ & \begin{tabular}{|l|}
$03^{\circ} 48^{\prime} 7.5^{\prime \prime} \mathrm{S}$ \\
$73^{\circ} 27^{\prime} 32.4^{\prime \prime} \mathrm{O}$
\end{tabular} & $0^{\circ}$ & & & $\mathrm{x}$ & $\mathrm{x}$ & $\mathrm{x}$ & $\mathrm{x}$ \\
\hline 4 & $\begin{array}{l}\text { Comunidad de Mishana, } \\
\text { rìo Nanay (Terraza) }\end{array}$ & $\begin{array}{l}03^{\circ} 53^{\prime} 92.6^{\prime \prime} \mathrm{S} \\
73^{\circ} 29^{\prime} 125^{\prime \prime} \mathrm{O}\end{array}$ & $190^{\circ}$ & & & $\mathrm{X}$ & $\mathrm{x}$ & $\mathrm{x}$ & $\mathrm{x}$ \\
\hline 5 & $\begin{array}{l}\text { Comunidad de Mishana, } \\
\text { rìo Nanay(Varillal) }\end{array}$ & & & & & $\mathrm{x}$ & $\mathrm{x}$ & & \\
\hline 6 & $\begin{array}{l}\text { Carretera Iquitos-Nauta } \\
\text { km } 46 \text { (Ex-Petroleros) }\end{array}$ & $\begin{array}{l}04^{\circ} 033^{\prime} 31^{\prime \prime} \mathrm{S} \\
73^{\circ} 27^{\prime} 23^{\prime \prime} \mathrm{O} \\
\end{array}$ & $300^{\circ}$ & & & $\mathrm{x}$ & $\mathrm{x}$ & $\mathrm{x}$ & $\mathrm{x}$ \\
\hline 7 & $\begin{array}{l}\text { Panguana II zona, } \\
\text { río Amazonas }\end{array}$ & $\begin{array}{l}03^{\circ} 55^{\prime} 23.9 ' \mathrm{~S} \\
73^{\circ} 07^{\prime} 42.3^{\prime \prime} \mathrm{O}\end{array}$ & $45^{\circ}$ & & & $\mathrm{X}$ & $\mathrm{x}$ & & \\
\hline 8 & $\begin{array}{l}\text { Comunidad de San } \\
\text { Antonio, río Marañon }\end{array}$ & $\begin{array}{l}04^{\circ} 32 ' 21.6 ” \mathrm{~S} \\
73^{\circ} 37^{\prime} 54.8^{\prime \prime} \mathrm{O}\end{array}$ & $350^{\circ}$ & & & $\mathrm{x}$ & $\mathrm{X}$ & $\mathrm{x}$ & $\mathrm{x}$ \\
\hline 9 & $\begin{array}{l}\text { Comunidad de Santa } \\
\text { Cecilia, río Maniti }\end{array}$ & $\begin{array}{l}03^{\circ} 56^{\prime} 13.4^{\prime \prime} \mathrm{S} \\
72^{\circ} 54^{\prime} 13.2^{\prime \prime} \mathrm{O}\end{array}$ & $90^{\circ}$ & & & $\mathrm{x}$ & $\mathrm{x}$ & $\mathrm{x}$ & $\mathrm{x}$ \\
\hline
\end{tabular}

\begin{tabular}{|c|c|c|c|c|c|c|c|c|c|}
\hline \multicolumn{10}{|c|}{ Zona de Pampa Hermosa } \\
\hline Transecto & Ubicación & Coordenadas & Orientación & Melastomatáceas & Helechos & Palmeras & Hormigas & Anuros & Aves \\
\hline 1 & $\begin{array}{l}\text { Santa Lucía 1, margen } \\
\text { izquierda del río } \\
\text { Cushabatay }\end{array}$ & $\begin{array}{l}07^{\circ} 10^{\prime} 01.4^{\prime \prime} \mathrm{S} \\
75^{\circ} 18^{\prime} 41.5^{\prime \prime} \mathrm{O}\end{array}$ & $300^{\circ}$ & $\mathrm{x}$ & $\mathrm{x}$ & $\mathrm{x}$ & & & \\
\hline 2 & $\begin{array}{l}\text { Santa Lucía 2, margen } \\
\text { izquierda del río } \\
\text { Cushabatay }\end{array}$ & $\begin{array}{l}07^{\circ} 09^{\prime} 50.1^{\prime \prime} \mathrm{S} \\
75^{\circ} 18^{\prime} 40.5^{\prime \prime} \mathrm{O}\end{array}$ & $20^{\circ}$ & $\mathrm{x}$ & $\mathrm{x}$ & $\mathrm{x}$ & & & \\
\hline 3 & $\begin{array}{l}\text { Pampa Hermosa 1, } \\
\text { por detrás del pueblo }\end{array}$ & $\begin{array}{l}\text { 07¹1'33.7" S } \\
75^{\circ} 19^{\prime} 13.6^{\prime \prime} \mathrm{O}\end{array}$ & $250^{\circ}$ & $\mathrm{x}$ & $\mathrm{x}$ & $\mathrm{x}$ & & & \\
\hline 4 & $\begin{array}{l}\text { Pampa Hermosa } 2, \\
\text { por detrás del pueblo }\end{array}$ & $\begin{array}{l}07^{\circ} 12 ' 36.4^{\prime \prime} \mathrm{S} \\
75^{\circ} 18,46.4^{\prime \prime} \mathrm{O}\end{array}$ & $220^{\circ}$ & $\mathrm{x}$ & $\mathrm{x}$ & $\mathrm{x}$ & & & \\
\hline 5 & $\begin{array}{l}\text { Comunidad de Isolaya } \\
1 \text {, rio Cushabatay }\end{array}$ & $\begin{array}{l}07^{\circ} 14^{\prime} 36.7^{\prime \prime} \mathrm{S} \\
75^{\circ} 20^{\prime} 44.05^{\prime \prime} \mathrm{O}\end{array}$ & $350^{\circ}$ & $\mathrm{x}$ & $\mathrm{x}$ & $\mathrm{x}$ & & & \\
\hline 6 & $\begin{array}{l}\text { Comunidad de Isolaya } \\
2 \text {, río Cushabatay }\end{array}$ & $\begin{array}{l}07^{\circ} 15,59.5^{\prime \prime} \mathrm{S} \\
75^{\circ} 21 ' 11.6^{\prime \prime} \mathrm{O}\end{array}$ & $150^{\circ}$ & $\mathrm{x}$ & $\mathrm{x}$ & $\mathrm{x}$ & & & \\
\hline 7 & $\begin{array}{l}\text { Comunidad deIsolaya } \\
3 \text {, río Cushabatay }\end{array}$ & \begin{tabular}{|c|}
$07^{\circ} 15^{\prime} 10^{\prime \prime} \mathrm{S}$ \\
$75^{\circ} 211^{\prime} 44.5^{\prime \prime} \mathrm{O}$
\end{tabular} & $300^{\circ}$ & $\mathrm{x}$ & $\mathrm{x}$ & $\mathrm{x}$ & & & \\
\hline 8 & $\begin{array}{l}\text { Comunidad de Olaya, } \\
\text { río Ucayali }\end{array}$ & $\begin{array}{l}07^{\circ} 02 ' 20.4^{\prime \prime} \mathrm{S} \\
75^{\circ} 11^{\prime} 06.4^{\prime \prime} \mathrm{O}\end{array}$ & $30^{\circ}$ & $\mathrm{x}$ & $\mathrm{x}$ & $\mathrm{x}$ & & & \\
\hline
\end{tabular}




\begin{tabular}{|c|c|c|c|c|c|c|c|c|c|}
\hline \multicolumn{10}{|c|}{ Zona de carretera $H$. Iñapari } \\
\hline Transecto & Ubicación & $\begin{array}{c}\text { Coordenadas } \\
\text { UTM }\end{array}$ & Orientación & Melastomatáceas & Helechos & Palmeras & Hormigas & Anuros & Aves \\
\hline 1 & $\begin{array}{l}\text { Comunidad de } \\
\text { San Lorenzo }\end{array}$ & $\begin{array}{c}465660 \\
8736213\end{array}$ & $0^{\circ}$ & $\mathrm{x}$ & $\mathrm{x}$ & $\mathrm{x}$ & $\mathrm{x}$ & $\mathrm{x}$ & $\mathrm{x}$ \\
\hline 2 & $\begin{array}{l}\text { Comunidad de } \\
\text { San Lorenzo }\end{array}$ & $\begin{array}{l}465665 \\
873666\end{array}$ & $220^{\circ}$ & $\mathrm{x}$ & $\mathrm{x}$ & $\mathrm{x}$ & & & \\
\hline 3 & $\begin{array}{l}\text { Comunidad de } \\
\text { San Lorenzo }\end{array}$ & $\begin{array}{c}469199 \\
8727116\end{array}$ & $40^{\circ}$ & $\mathrm{X}$ & $\mathrm{x}$ & $\mathrm{x}$ & & & \\
\hline 4 & $\begin{array}{l}\text { Comunidad de } \\
\text { Iñapari }\end{array}$ & $\begin{array}{c}430898 \\
8781324\end{array}$ & $120^{\circ}$ & $\mathrm{x}$ & $\mathrm{x}$ & $\mathrm{x}$ & $\mathrm{x}$ & & \\
\hline 5 & $\begin{array}{l}\text { Comunidad de } \\
\text { Iñapari }\end{array}$ & $\begin{array}{c}432466 \\
8785689\end{array}$ & $20^{\circ}$ & $\mathrm{x}$ & $\mathrm{x}$ & $\mathrm{x}$ & & & \\
\hline 6 & $\begin{array}{l}\text { Comunidad de } \\
\text { Iñapari }\end{array}$ & $\begin{array}{c}439550 \\
8780869\end{array}$ & $150^{\circ}$ & $\mathrm{x}$ & $\mathrm{x}$ & $\mathrm{x}$ & & & \\
\hline 7 & $\begin{array}{l}\text { Comunidad de } \\
\text { Mavila }\end{array}$ & $\begin{array}{c}442837 \\
8753031\end{array}$ & $350^{\circ}$ & $\mathrm{x}$ & $\mathrm{x}$ & $\mathrm{x}$ & & & \\
\hline 8 & $\begin{array}{l}\text { Comunidad de } \\
\text { Mavila }\end{array}$ & $\begin{array}{c}484393 \\
8684064\end{array}$ & $0^{\circ}$ & $\mathrm{x}$ & $\mathrm{x}$ & $\mathrm{x}$ & & & \\
\hline 9 & $\begin{array}{l}\text { Comunidad de } \\
\text { Santa Rosa }\end{array}$ & $\begin{array}{c}486572 \\
8672422\end{array}$ & $90^{\circ}$ & $\mathrm{x}$ & $\mathrm{x}$ & $\mathrm{x}$ & & & \\
\hline 10 & $\begin{array}{l}\text { Comunidad de } \\
\text { Alegría }\end{array}$ & $\begin{array}{c}485422 \\
8655529\end{array}$ & $110^{\circ}$ & $\mathrm{x}$ & $\mathrm{x}$ & $\mathrm{X}$ & & & \\
\hline
\end{tabular}

\begin{tabular}{|c|c|c|c|c|c|c|c|c|c|}
\hline \multicolumn{10}{|c|}{ Zona de Tambopata } \\
\hline Transecto & Ubicación & $\begin{array}{l}\text { Coordenadas } \\
\text { UTM }\end{array}$ & Orientación & Melastomatáceas & Helechos & Palmeras & Hormigas & Anuros & Aves \\
\hline 1 & $\begin{array}{l}\text { Río Tambopata, } \\
\text { margen derecha } \\
\text { (Albergue Posada) }\end{array}$ & $\begin{array}{c}467489 \\
8584711\end{array}$ & $0^{\circ}$ & $\mathrm{x}$ & $\mathrm{x}$ & $\mathrm{x}$ & & & \\
\hline 2 & $\begin{array}{l}\text { Río Tambopata, } \\
\text { margen izquierda }\end{array}$ & $\begin{array}{c}462205 \\
8581869\end{array}$ & $30^{\circ}$ & $\mathrm{x}$ & $\mathrm{X}$ & $\mathrm{x}$ & & & \\
\hline 3 & $\begin{array}{l}\text { Río Tambopata, } \\
\text { margen derecha }\end{array}$ & $\begin{array}{c}456026 \\
8576520\end{array}$ & $100^{\circ}$ & $\mathrm{x}$ & $\mathrm{x}$ & $\mathrm{x}$ & & & \\
\hline 4 & $\begin{array}{l}\text { Río Tambopata, } \\
\text { margen izquierda }\end{array}$ & $\begin{array}{l}0443691 \\
8575362\end{array}$ & $300^{\circ}$ & $\mathrm{x}$ & $\mathrm{x}$ & $\mathrm{x}$ & & & \\
\hline 5 & $\begin{array}{l}\text { Río Tambotapa, } \\
\text { margen izquierda }\end{array}$ & $\begin{array}{c}432479 \\
8547233\end{array}$ & $320^{\circ}$ & $\mathrm{x}$ & $\mathrm{x}$ & $\mathrm{x}$ & & & \\
\hline 6 & $\begin{array}{l}\text { Río Tambopata, } \\
\text { margen izquierda }\end{array}$ & $\begin{array}{c}432754 \\
8549074\end{array}$ & $0^{\circ}$ & $\mathrm{x}$ & $\mathrm{x}$ & $\mathrm{x}$ & & & \\
\hline 7 & $\begin{array}{l}\text { Río Tambopata, } \\
\text { margen derecha }\end{array}$ & $\begin{array}{c}435279 \\
8545797\end{array}$ & $160^{\circ}$ & $\mathrm{x}$ & $\mathrm{x}$ & $\mathrm{x}$ & & & \\
\hline 8 & $\begin{array}{l}\text { Río Tambopata, } \\
\text { margen izquierda }\end{array}$ & $\begin{array}{c}431315 \\
8543494\end{array}$ & $250^{\circ}$ & $\mathrm{x}$ & $\mathrm{x}$ & $\mathrm{x}$ & & & \\
\hline 9 & $\begin{array}{l}\text { Río Tambopata, } \\
\text { margen izquierda }\end{array}$ & $\begin{array}{c}432779 \\
8548456\end{array}$ & $0^{\circ}$ & $\mathrm{x}$ & $\mathrm{x}$ & $\mathrm{x}$ & & & \\
\hline
\end{tabular}


Las zonas de muestreo fueron seleccionadas principalmente sobre la base de sus características geológicas. La idea era muestrear en tierra firme, en zonas donde los resultados podrían ser generalizables a otras zonas parecidas. Naturalmente, las zonas fueron seleccionadas considerando también la mayor facilidad logística posible. Además, dentro de cada zona se trató de ubicar los lugares de muestreo de tal manera que abarcaran la mayor cantidad posible de la variación local en los valores de reflectancia en imágenes de Landsat TM.

La zona de Andoas se ubica en el abanico del Pastaza, que cubre un área grande en la zona fronteriza entre Ecuador y Perú. En sus alrededores se encuentran aparentemente sedimentos fluviales más antiguos y con material volcánico. Los sedimentos volcánicos son supuestamente mucho más ricos en nutrientes, y por eso potencialmente puede existir un cambio en la productividad general, acompañado por un cambio en la composición de especies, cuando se mueve del área de sedimentos volcánicos al área de sedimentos fluviales más pobres en nutrientes. El área de Andoas fue escogida para indagar sobre el efecto de los sedimentos volcánicos en la composición de las especies.

A lo largo de las laderas de los Andes se observa típicamente que cerca de las montañas mismas se encuentran sedimentos relativamente antiguos, porque el levantamiento de los Andes ha canalizado fuertemente los ríos impidiendo la sedimentación fluvial. Más lejos de las montañas el terreno se vuelve más plano, y consecuentemente los ríos empiezan a tener cauces más meándricos, formando planicies más grandes de inundación. Estas planicies se convierten a terrazas (tierra firme), a través de cambios climáticos y/o inclinaciones del terreno creadas por el tectonismo. Sumando todo esto, se puede ver un cambio gradual de edad en los sedimentos superficiales, de tal manera que los sedimentos más antiguos están más cerca a los Andes y los más jóvenes se encuentran siempre más lejos de las montañas. Este gradiente se repite prácticamente en toda la franja en la base de los Andes. Para muestrear este gradiente, se hizo trabajos de campo a lo largo de los ríos Tambopata y Cushabatay (Pampa Hermosa).

La quinta zona de muestreo fue en el área de la carretera Puerto Maldonado-Iñapari. Esta zona fue seleccionada porque aparentemente atraviesa un cambio de sedimentos fluviales pleistocénicos a sedimentos semimarinos/ lacustres de la época miocena. Este límite corre del sur de Perú al noreste o norte cruzando los departamentos de Acre y Amazonas de Brasil y llegando otra vez al Perú más o menos en la zona de Caballococha (M. Räsänen, com. pers.). Este es un límite geológico que aparentemente caracteriza en una escala grande toda la Amazonía occidental. Actualmente se sabe muy poco de su efecto en la flora y fauna, pero es posible que el cambio observado en los mamíferos pequeños a lo largo del río Juruá (Patton et al., 1994), o la diferenciación de la flora según los tipos del suelo en la zona de Iquitos (Ruokolainen y Tuomisto, 1998), sean expresiones de este fenómeno.

\subsection{Métodos de muestreo}

\section{Plantas}

Para el inventario de plantas, establecimos transectos de 500 × $5 \mathrm{~m}$ divididos en 20 sub-unidades de 25 x $5 \mathrm{~m}$. A lo largo de estos transectos registramos la ocurrencia y abundancia de los tres grupos de plantas. Dentro de cada zona de muestreo, colectamos por lo menos un espécimen representativo por especie y, además, siempre hicimos una colecta adicional cuando no estuvimos seguros de la identidad de la planta. De los helechos y palmeras registramos sólo individuos que tenían por lo menos una hoja más de $10 \mathrm{~cm}$ de longitud y que crecían en el suelo, y de las trepadoras o epifitas sólo las que tenían hojas a una altura máxima de dos metros sobre el suelo. De las melastomatáceas registramos todas las plantas que tenían hojas desarrolladas. Los espécimenes fueron identificados en el Herbario Amazonense (AMAZ) de la Universidad Nacional de la Amazonía Peruana (UNAP), Iquitos, mediante uso de claves y comparación con muestras de colección. Cuando hubo espécimenes que no pudimos identificar, los comparamos con otros no identificados y asignamos a todas estas muestras diferentes números de morfoespecies. En los análisis tratamos a las especies identificadas y morfoespecies de igual manera, y en el texto nos referimos a ambas con el término de especie. 
Aves

Para el inventario de aves utilizamos el método de transecto lineal y una modificación de éste a manera de un sistema de trochas en parrilla. Dependiendo de la topografía, utilizamos un transecto lineal de $2000 \mathrm{~m}$, cuando el terreno presentaba dificultades para hacer una parrilla, o un sistema de cuatro trochas paralelas de $500 \mathrm{~m}$ (medidas cada $25 \mathrm{~m}$ ) y separadas entre sí por $300 \mathrm{~m}$, cuando el terreno era de fácil accesibilidad.

El tiempo de evaluación fue de ocho días en cada localidad. Así, para el caso del sistema en parrilla, en el primer día iniciamos la evaluación en el transecto 1, continuando en el 2, 3 y 4; el segundo día iniciamos en el transecto 2, continuando con el 3, 4 y 1, y así sucesivamente hasta el cuarto día, después del cual repetimos el orden de recorridos. Cuando el inventario se realizó en el transecto lineal, el recorrido se inició en $0 \mathrm{~m}$, el segundo día en $500 \mathrm{~m}$ y así sucesivamente hasta $2000 \mathrm{~m}$.

Los registros fueron auditivos y visuales. La detección de las aves varía en función a la hora, siendo las primeras horas de la mañana adecuadas para la detección de aves de sotobosque, cuya actividad declina mientras que la detectabilidad de aves de dosel se incrementa en estas mismas horas. Hicimos recorridos a paso lento observando ambos lados del transecto y anotando las aves presentes. Registramos las aves observadas o escuchadas hasta una distancia máxima perpendicular de $150 \mathrm{~m}$ de la trocha; los datos considerados fueron sexo, cuando fue posible, tipo de contacto (visual o auditivo), hora de registro, distancia del contacto de la trocha y estrato del bosque en que el ave se encontraba (suelo, estrato bajo, estrato medio o dosel). Para los objetivos de este estudio sólo utilizamos datos de presencia y abundancia de cada especie.

\section{Anuros}

La búsqueda de anuros se realizó en horas diurnas y nocturnas, mediante registro visual y auditivo en uno de los transectos de 500 m utilizados para el inventario de aves. El inventario diurno consistió en búsqueda de anuros mediante la remoción de hojarasca y restos de madera en descomposición. El tiempo de inventario durante el día fue de tres horas en un recorrido de $100 \mathrm{~m}$ del transecto. En la noche se empleó de dos a tres horas, avanzando 100 a $150 \mathrm{~m}$. Utilizamos una linterna frontal para el muestreo, realizando la búsqueda de individuos hasta una altura de $3 \mathrm{~m}$. Las distancias recorridas dependían de la cantidad de restos de materia orgánica en descomposición (hojas, raíces, ramas secas, etc.), vegetación del sotobosque (tupida o clara) y la topografía (ondulada o plana). En los transectos se registró todos los individuos presentes. Cuando la identificación taxonómica en el campo no resultó posible, se colectó especimenes para su identificación en el laboratorio.

\section{Hormigas}

El inventario de hormigas se realizó en uno de los transectos para la evaluación de aves, ampliando éste a 625 $\mathrm{m}$. En cada $25 \mathrm{~m}$ recogimos una muestra de un metro cuadrado de hojarasca del suelo. Las muestras fueron cernidas en el campo y el producto colocado en bolsas de tela para transportarlas al campamento. El contenido fue vaciado en trampas Winkler (25 trampas) y dejado durante 48 horas, al cabo de las cuales colectamos las hormigas que cayeron en pequeñas bolsas plásticas, conteniendo alcohol al 70\%, ubicadas en la parte terminal de la trampa. Con el uso de un microscopio estéreo separamos las hormigas de la tribu Dacetini para su identificación.

\section{Observaciones ambientales}

Para buscar relaciones entre la composición de especies de plantas y animales con algunas características ambientales, medimos la topografía del terreno, registramos el área basal y recolectamos tres muestras de suelo por cada transecto, al inicio, a la mitad y al final. El análisis químico de las muestras de suelo se encuentra todavía en proceso, por lo que esta variable no fue utilizada en la interpretación de los resultados aquí reportados.

\section{Imágenes de satélite}

En este estudio, se calculó la correlación de Mantel entre el patrón de semejanzas y diferencias en la composición de especies de helechos y los patrones de valores de reflectancia de la imagen de satélite de Landsat TM para la 
zona de Andoas. Para obtener el valor de reflectancia de cada lugar de inventario, dibujamos en la imagen de satélite un cuadrángulo de $1 \mathrm{~km}$ cuadrado de superficie encima de cada línea de $500 \mathrm{~m}$ de inventario de plantas. Cuando hubo nubes, carreteras, agua o algo obviamente diferente al bosque inventariado dentro del cuadrángulo, eliminamos esas áreas del cuadrángulo. Después registramos los promedios de reflectancia dentro de cada cuadrángulo en cuatro bandas, $3,4,5$, y 7 , que están disponibles en el mosaico de imágenes de satélite de la selva baja, procesado en el proyecto BIODAMAZ, y disponible en el Sistema de Información de Diversidad Biológica y Ambiental de la Amazonía Peruana (SIAMAZONIA; www.siamazonia.org.pe).

\section{Análisis numéricos}

Los análisis numéricos de diferencias y semejanzas están basados en el cálculo de distancias florísticas, faunísticas o ambientales entre pares de lugares de inventario. Para calcular las distancias florísticas y faunísticas, utilizamos los índices de Sørensen y Steinhaus (Legendre y Legendre, 1998; BIODAMAZ, 2004). Estos dos índices son matemáticamente semejantes excepto que el de Sørensen toma en cuenta sólo la presencia y ausencia de las especies, mientras que el índice de Steinhaus usa la información de abundancias de las especies. En el caso de datos ambientales, usamos la distancia euclidiana. En el caso de tener que incluir más de una variable ambiental en el cálculo de la distancia euclidiana, estandardizamos cada variable para tener el promedio 0 y varianza 1 , para que las variables tuvieran un peso igual en el cálculo de la distancia.

En la zona de Iquitos, usamos los resultados de los análisis químicos del suelo presentados por Ruokolainen y Tuomisto (1998), para medir las distancias ambientales entre los lugares de muestreo. Estas distancias euclidianas están basadas en el contenido de aluminio, potasio, calcio, magnesio y sodio, porcentaje de arena, porcentaje de reducción del peso después de quemar el suelo en una temperatura de $420{ }^{\circ} \mathrm{C}$ (una aproximación del contenido de carbón) y pH.

Con base en estas distancias, se puede formar 'mapas' que presentan los lugares de estudio como puntos, de tal manera que dos lugares semejantes (poca distancia florística, faunística o ambiental) aparecen cercanos entre sí, y dos lugares diferentes se sitúan bien aparte uno del otro. Para generar estos mapas, utilizamos el método de ordenación por escalarización multidimensional no métrica (NMS; Legendre y Legendre, 1998). Decidimos $a$ priori el número de dimensiones de las ordenaciones a dos, porque nuestro interés era solamente ilustrar los patrones de semejanza y diferencia entre los lugares de inventario.

Para estudiar las relaciones entre cambios florístico-faunísticos y cambios ambientales, utilizamos la prueba de Mantel (Legendre y Legendre, 1998; BIODAMAZ, 2004). En la prueba de Mantel se calcula la correlación linear de Pearson entre las medidas de distancia (por ejemplo, distancias florísticas y distancias ambientales) calculadas entre pares de lugares de inventario. La probabilidad de error se estima a través de aleatorizaciones de una de las tablas de distancias. Aleatorización es la mejor opción para estimar la probabilidad de error, porque los valores de distancia dentro de una tabla no son independientes entre sí y por eso no se puede calcular el número de grados de libertad. Si se ha observado, por ejemplo, que los lugares 1 y 2 , más 1 y 3 son muy semejantes entre sí, entonces se puede anticipar que la comparación entre los lugares 2 y 3 resulta en gran semejanza. En otras palabras, los valores de distancia calculados entre los pares de lugares no son observaciones independientes.

\section{RESULTADOS}

Para investigar patrones de diferencias y semejanzas a nivel de la macroregión de selva baja, comparamos la riqueza de especies, abundancia relativa y similitudes taxonómicas de los tres grupos de plantas indicadoras entre las cuatro zonas donde fueron inventariados (Andoas, Pampa Hermosa, Iñapari y Tambopata). Las palmeras fueron inventariadas en una zona adicional (Iquitos).

En este estudio se registró un total de 103 especies y 17128 individuos de palmeras; 169 especies y 5819 individuos de melastomáceas; y 147 especies y 54816 individuos de helechos (Anexos 1, 2, 3). 


\subsection{Riqueza de especies}

Para todos los grupos de plantas, hubo una marcada diferencia en riqueza de especies entre zonas (Cuadro 3). Iquitos reportó el mayor número de especies de palmeras; pero para las cuatro zonas donde todos los grupos fueron inventariados, Andoas fue la zona de mayor riqueza de especies para todos los grupos de plantas. Asimismo, Andoas reportó el mayor número y proporción de especies "únicas", es decir especies que no fueron registradas en las otras zonas (Cuadro 3). Tambopata fue la segunda zona más rica en especies para todos los grupos, y Pampa Hermosa fue la zona de menor número de especies (Cuadro 3).

Cuadro 3. Riqueza de especies en cinco zonas de muestreo de palmeras, melastomatáceas y helechos ${ }^{1}$.

\begin{tabular}{|c|c|c|c|c|c|}
\hline $\mathrm{N}^{\circ}$ de & ectos & $\begin{array}{l}\mathrm{N}^{\circ} \text {. de spp } \\
\text { registradas }\end{array}$ & $\begin{array}{c}\mathrm{N}^{\circ} \cdot \text { promedio de spp } \\
\text { por transecto }\end{array}$ & $\begin{array}{c}\mathrm{N}^{\circ} \text {. de spp } \\
\text { únicas }\end{array}$ & $\%$ de spp. únicas \\
\hline \multicolumn{6}{|c|}{ Palmeras (N = $103 \mathrm{spp})$} \\
\hline Andoas & 11 & 65 & 22.4 & 30 & $46.1 \%$ \\
\hline Iquitos & 10 & 68 & 21.5 & 10 & $14.7 \%$ \\
\hline P. Hermosa & 8 & 21 & 9.0 & 4 & $19.0 \%$ \\
\hline Iñapari & 10 & 29 & 14.4 & 5 & $17.2 \%$ \\
\hline Tambopata & 9 & 39 & 15.7 & 6 & $15.8 \%$ \\
\hline \multicolumn{6}{|c|}{ Melastomataceas ( $\mathrm{N}=169 \mathrm{spp})$} \\
\hline Andoas & 11 & 135 & 37.9 & 93 & $68.9 \%$ \\
\hline P. Hermosa & 8 & 14 & 2.4 & 2 & $14.3 \%$ \\
\hline Iñapari & 10 & 20 & 4.0 & 6 & $30.0 \%$ \\
\hline Tambopata & 9 & 63 & 15.3 & 18 & $28.6 \%$ \\
\hline \multicolumn{6}{|c|}{ Helechos (N = 147 spp) } \\
\hline Andoas & 11 & 94 & 27.4 & 65 & $69.1 \%$ \\
\hline P. Hermosa & 8 & 26 & 7.7 & 7 & $28.0 \%$ \\
\hline Iñapari & 10 & 38 & 12.2 & 8 & $23.5 \%$ \\
\hline Tambopata & 9 & 54 & 16.1 & 20 & $37.0 \%$ \\
\hline
\end{tabular}

${ }^{1}$ En la zona de Iquitos se inventarió sólo palmeras.

\subsection{Abundancia relativa}

De las palmeras, Geonoma deversa fue la especie más abundante, comprendiendo el 16.9\% de todos los registros; estuvo presente en todas las zonas excepto Pampa Hermosa. Oenocarpus bataua fue la segunda más abundante, comprendiendo el $9.2 \%$ de los registros.

En cuanto a las melastomatáceas, la más abundante fue Maieta guianensis (5.9\%), seguida por Miconia schunkei (5.3\%); pero ambas especies sólo fueron encontradas en Andoas y Tambopata.

De los helechos, Adiantum cf. petiolatum fue con diferencia la especie más abundante, comprendiendo el $53.8 \%$ de los helechos registrados. Estuvo presente en todas las zonas salvo Andoas. Adiantum cf. poeppigianum fue la segunda (11.5\%), pero sólo fue registrada en Pampa Hermosa e Iñapari.

Como se puede apreciar en Cuadro 4, la abundancia relativa de las especies más comunes varía mucho entre zonas y grupos de plantas. 
Cuadro 4. Riqueza de especies en cinco zonas de muestreo de palmeras, melastomatáceas y helechos ${ }^{1}$.

\begin{tabular}{|c|c|c|c|}
\hline & & $\mathrm{N}^{\circ}$ Registros & Abundancia \% \\
\hline \multicolumn{4}{|l|}{ ANDOAS } \\
\hline Palmeras & Oenocarpus bataua & 3917 & 29.2 \\
\hline Melastomatáceas & Maieta guianensis & 4017 & 8.5 \\
\hline Helechos & Adiantum humile & 6992 & 16.3 \\
\hline \multicolumn{4}{|l|}{ PAMPA HERMOSA } \\
\hline Palmeras & Attalea phalerata & 2814 & 47.7 \\
\hline Melastomatáceas & Leandra longicoma & 103 & 18.4 \\
\hline Helechos & Adiantum cf poeppigianum & 8214 & 75.8 \\
\hline \multicolumn{4}{|l|}{ IÑAPARI } \\
\hline Palmeras & Geonoma deversa & 3420 & 38.6 \\
\hline Melastomatáceas & Miconia affinis & 212 & 17.0 \\
\hline Helechos & Adiantum cf petiolatum & 30451 & 94.3 \\
\hline \multicolumn{4}{|l|}{ TAMBOPATA } \\
\hline Palmeras & Geonoma deversa & 3566 & 41.8 \\
\hline Melastomatáceas & Miconia schunkei & 1487 & 17.2 \\
\hline Helechos & Lomariopsis nigropaleata & 9159 & 30.5 \\
\hline \multicolumn{4}{|l|}{ IQUITOS } \\
\hline Palmeras & Geonoma stricta & 3411 & 11.1 \\
\hline
\end{tabular}

\subsection{Similitudes florísticas}

Solo seis especies $(5.8 \%)$ de palmeras, cinco (3.0\%) de melastomatáceas y cuatro (2.7\%) de helechos fueron compartidas por las cuatro zonas donde se inventariaron todos los grupos de plantas, a saber:

Attalea maripa, Euterpe precatoria, Hyospathe elegans, Oenocarpus bataua y O. mapora (Arecaceae); Bellucia pentamera, Leandra longicoma, Miconia sp. ("eleagnoides larga"), M. nervosa y M. triplinervis (Melastomataceae); y Adiantum pulverulentum, Lomagramma guianensis, Lomariopsis nigropaleata y Polybotrya caudata (Pteridophyta).

En el Cuadro 5 se indican los porcentajes de especies compartidas entre cada par de zonas donde se inventarió todos los grupos de plantas. Como se puede apreciar, de las palmeras y helechos el mayor porcentaje de especies compartidas está entre las dos zonas geográficamente más cercanas entre sí - Iñapari y Tambopata -, mientras que en las melastomatáceas éste está entre las dos zonas más distantes entre sí - Andoas y Tambopata (ver las distancias geográficas en Cuadro 1). En las melastomatáceas el porcentaje de especies compartidas entre Pampa Hermosa e Iñapari también es comparativamente alto.

Cuadro 5. Porcentajes de especies compartidas entre todos los pares de zonas de muestreo.

\begin{tabular}{lccc}
\hline & PAMPA HERMOSA & IÑAPARI & TAMBOPATA \\
\hline Palmeras & \multirow{2}{*}{19.4} & 22.1 & 33.3 \\
Andoas & & 21.9 & 22.4 \\
P. Hermosa & & & 36.0 \\
Iñapari & & & \\
Melastomatáceas & 6.4 & 5.4 & 23.0 \\
Andoas & & 21.4 & 13.2 \\
P. Hermosa & & & 16.9 \\
Iñapari & & & \\
Helechos & 7.1 & 14.8 & 18.4 \\
Andoas & & 21.1 & 12.7 \\
P. Hermosa & & 35.3 \\
Iñapari & & & \\
\hline
\end{tabular}


En cuanto a la zona de Iquitos, donde sólo se inventarió palmeras, comparte especies principalmente con Andoas (52.9\%) y en menor proporción con Tambopata (35.4\%), Iñapari (29.3\%) y Pampa Hermosa (21.9\%).

Cuando incluimos en el análisis también la relativa abundancia de cada especie en cada zona, encontramos que para las melastomatáceas y los helechos la mayor similitud florística está entre Andoas y Tambopata (Figuras 2 y 3 ) y para las palmeras entre Iñapari y Tambopata por un lado y Andoas - Iquitos por otro lado (Figura 4).

\subsection{Composición florística y área basal del bosque}

Para los helechos se calculó la correlación entre las matrices de abundancia de helechos (índice de Steinhaus) y el área basal del bosque para todas las cuatro zonas de muestreo. Los resultados indicaron una correlación baja en Andoas $(\mathrm{r}=0.33, \mathrm{p}=0.1)$ y Tambopata $(\mathrm{r}=0.26, \mathrm{p}=0.09)$; no hubo correlación en Pampa Hermosa $(\mathrm{r}=$ $0.07, \mathrm{p}=0.43)$ e Iñapari $(\mathrm{r}=-0.012, \mathrm{p}=0.3)$. Vale notar que una correlación negativa en el análisis de prueba de Mantel con datos florísticos o faunísticos indica siempre que no haya relación entre las variables. Una correlación negativa significaría, que cuando más diferentes son los lugares de muestreo en términos de la variable ambiental (área basal en este caso), más semejantes son en su composición de especies, suposición que obviamente no tiene ningún sentido ecológico.

\subsection{Riqueza de especies de animales en la sub-región de Andoas - Iquitos}

En la sub-región de Andoas-Iquitos fueron realizados inventarios de animales en nueve localidades (uno en Andoas y ocho en Iquitos; ver Figura 5). Se registró la presencia de un total de 230 especies de aves, 57 de anuros y 30 de hormigas (para listados de especies y número de ejemplares registrados, ver Anexos 4, 5 y 6).

El Cuadro 6 indica el número de especies registradas de cada grupo inventariado para cada localidad. Como se puede ver, Manití reporta una riqueza de especies ligeramente mayor que las otras localidades, salvo para las hormigas, que registraron el mayor número de especies en Gengén. El mayor número de especies "únicas" de aves y anuros probablemente se debe al efecto de barrera del río Amazonas, ya que para estos grupos fue la única localidad inventariada en la margen derecha del Amazonas.

a

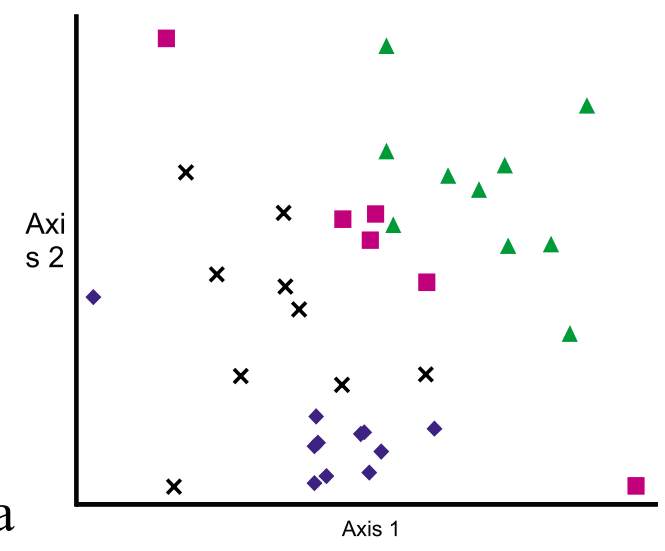

$\mathrm{b}$

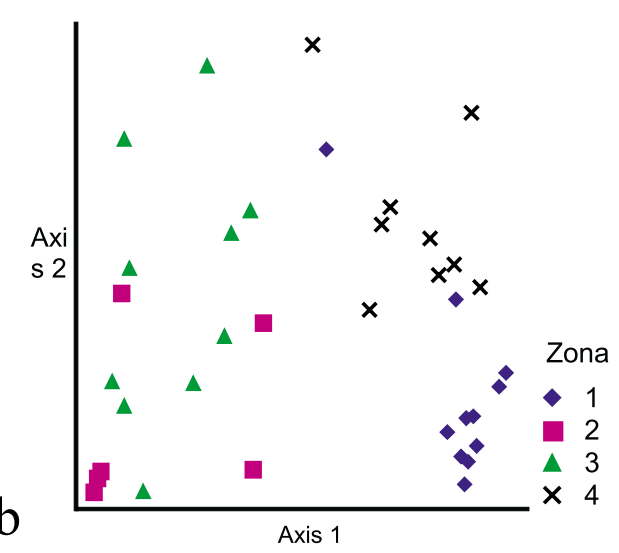

Figura 2. Ordenación por escalarización multidimensional no métrica NMS (Non-Metric Multidimensional Scaling) de la composición de especies de Melastomataceae en las cuatro zonas de muestreo (a) basada en datos de presencia y abundancia utilizando el índice de Steinhaus y (b) presencia y ausencia utilizando el índice de Sørensen. Cada símbolo representa uno de los 36 transectos de 500 x 5 m. Zona 1: Andoas; Zona 2: Pampa Hermosa; Zona 3: Iñapari; Zona 4: Tambopata. 

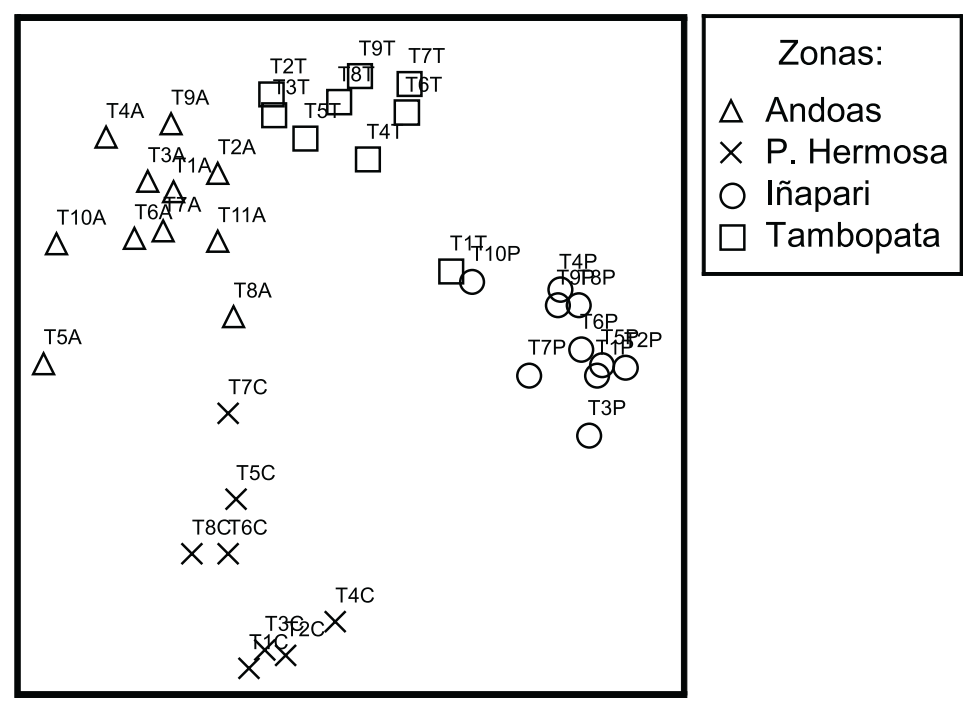

Figura 3. Ordenación por escalarización multidimensional no métrica NMS (Non-Metric Multidimensional Scaling) a base del índice de Steinhaus de la composición florìstica de helechos en cuatro zonas de muestreo. Cada símbolo representa un transecto de inventario

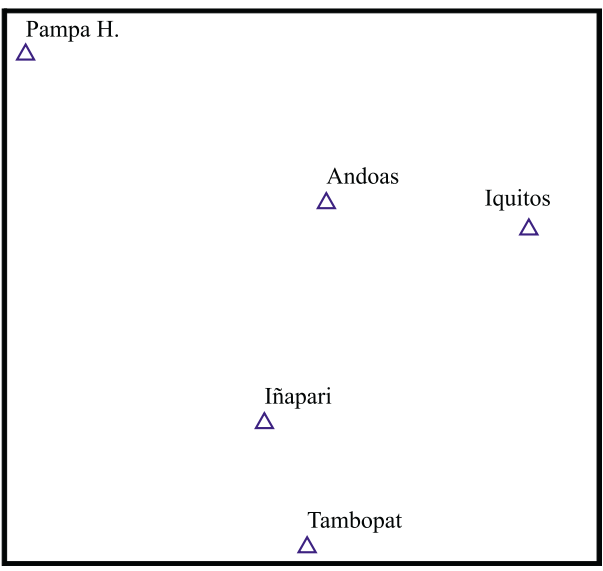

a.

Figura 4. (a) Ordenación por escalarización multidimensional no métrica NMS (Non-Metric Multidimensional Scaling) a base del índice de Steinhaus de la composición florística de palmeras en cinco zonas muestreadas. (b) Cada símbolo representa un transecto de inventario.
Zonas de muestreo

$\triangle$ Andoas

$\triangle$ Iquitos

19PH $17 \mathrm{PH}$

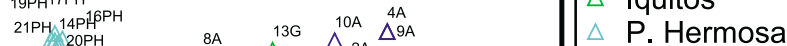

$\triangle$ Tambopata

$\triangle$ Iñapari

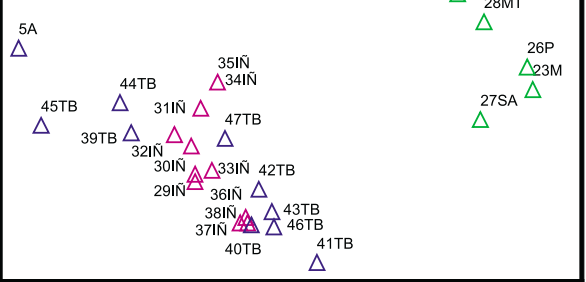

b. 


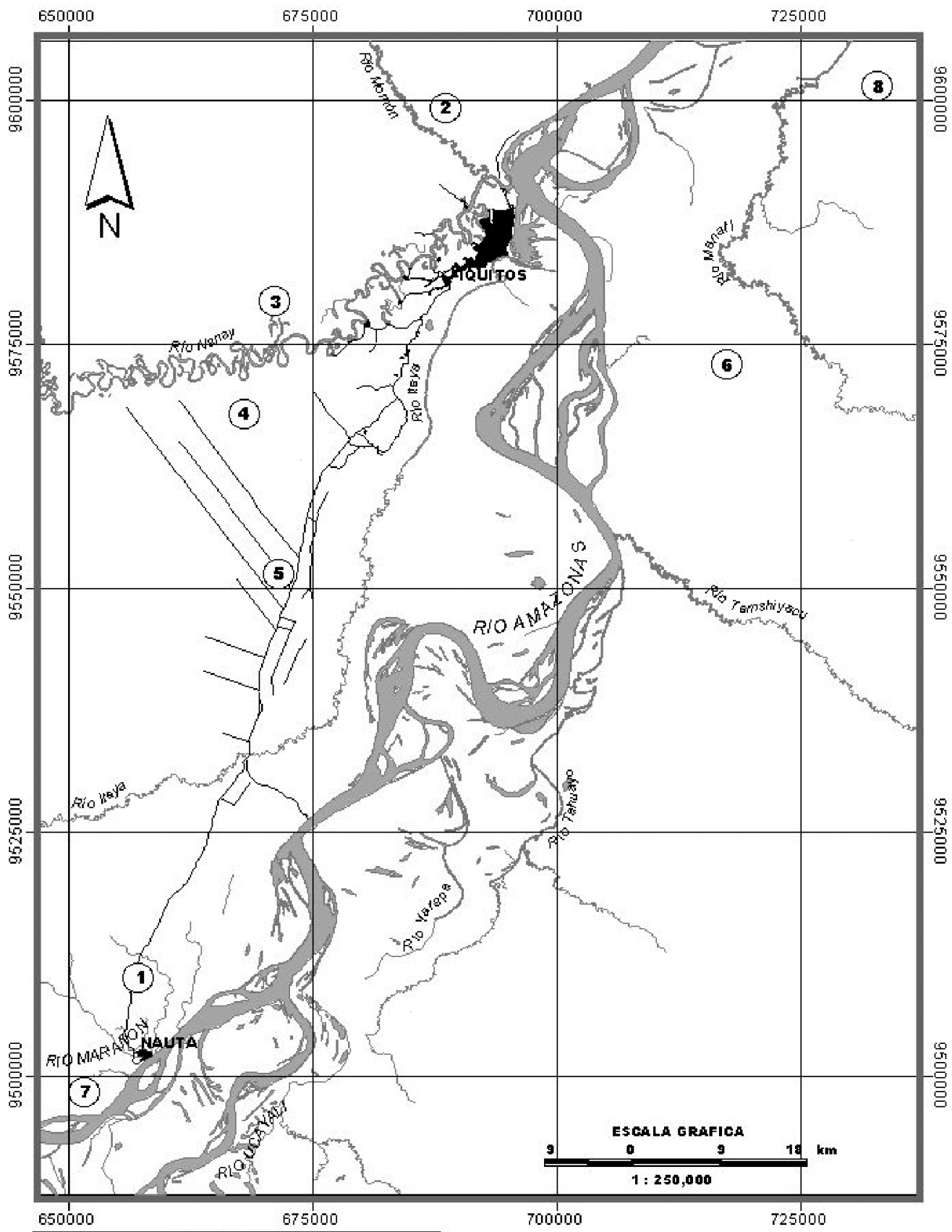

\section{LEYENDA}

(1) Carretera Nauta - Iquitos km. 9.5

$(2)$ Gengén, bajo río Momón

(3) Tarapoto, bajo Nanay

(9) Mishana, rio Nanay

(s) Ex-Petroleros

(6) Fanguana, 2da. zona, rio Amazonas

$\fallingdotseq$ San Antonio, bajo río Marañón

(a) Santa Cecilia, bajo rio Manatí

\section{SIGNOS CONVENCIONALES}

- Centros Poblados Urbanos Cuerpos de Agua

Ríos Secundarios y Quebradas

Carretera lquitos - Nauta

Figura 5. Mapa de la Zona de Iquitos. 
Cuadro 6. Número de especies registradas en nueve localidades de inventario de grupos indicadores en la subregión de Andoas - Iquitos ${ }^{1}$.

\begin{tabular}{lcccccccc}
\hline & \multicolumn{2}{c}{ AVES } & \multicolumn{2}{c}{ ANUROS } & \multicolumn{2}{c}{ HORMIGAS } & \multicolumn{2}{c}{ PALMERAS } \\
\hline & No. de spp & $\begin{array}{c}\text { (spp } \\
\text { única })\end{array}$ & No. spp & $\begin{array}{c}\text { (spp } \\
\text { únicas) }\end{array}$ & No. spp & $\begin{array}{c}(\mathrm{spp} \\
\text { únicas })\end{array}$ & No. spp & $\begin{array}{c}\text { (spp } \\
\text { únicas) }\end{array}$ \\
\hline Andoas & 123 & $(12)$ & 16 & $(2)$ & 12 & $(2)$ & $22,4^{2}$ & \\
San Antonio & 115 & $(8)$ & 15 & $(1)$ & 8 & $(0)$ & 15 & $(2)$ \\
Nauta & 109 & $(8)$ & 13 & $(2)$ & 8 & $(0)$ & 26 & $(2)$ \\
Ex - Petroleros & 67 & $(1)$ & 15 & $(3)$ & 7 & $(0)$ & 21 & $(7)$ \\
Mishana & 112 & $(8)$ & 16 & $(3)$ & 10 & $(0)$ & 17 & $(2)$ \\
Mishana III & - & & - & & 6 & $(1)$ & 18 & $(2)$ \\
Tarapoto & 113 & $(5)$ & 22 & $(3)$ & 8 & $(1)$ & 24 & $(3)$ \\
Gengén & 116 & $(5)$ & 22 & $(4)$ & 15 & $(3)$ & 19 & $(2)$ \\
Panguana & - & & - & & 8 & $(3)$ & 20 & $(0)$ \\
Manití & 128 & $(18)$ & 22 & $(8)$ & 11 & $(2)$ & $27,5^{3}$ & $(2,5)^{3}$ \\
\hline
\end{tabular}

${ }^{1}$ En Mishana III y Panguana sólo se inventarió hormigas y palmeras.

${ }^{2}$ Promedio para 11 transectos inventariados.

${ }^{3}$ Promedio para 2 transectos inventariados.

\subsection{Similitudes y diferencias faunísticas}

De los grupos faunísticos inventariados en la sub-región, solo 28 especies (12,2\%) de aves, 3 (10\%) de hormigas y ninguna de anuros fueron registradas en todas las localidades.

Como se puede observar en las respectivas matrices de similitud, presentadas en el Cuadro 7, para el conjunto de aves y anuros (pero no para las hormigas), los mayores porcentajes de especies compartidas se dan entre las localidades de Gengén, Tarapoto y Mishana. Son localidades comparativamente cercanas entre sí y ubicadas en la misma subcuenca (bajo Nanay; Figura 5), por lo que aparentemente hay una autocorrelación espacial entre estas localidades. Aparte de este caso, no se observa ningún patrón compartido entre los grupos inventariados. 
Cuadro 7. Porcentajes de especies compartidas entre todos los pares de localidades inventariadas en la subregión de Andoas - Iquitos.

\begin{tabular}{l|c|c|c|c|c|c|c}
\hline & Andoas & San Antonio & Nauta & Ex-Petroleros & Mishana & Tarapoto & Gengén \\
\hline Aves & & & & & & & \\
San Antonio & 52 & & & & & & \\
Nauta & 54 & 48 & & & & & \\
Ex-Petroleros & 39 & 44 & 40 & & & & \\
Mishana & 45 & 49 & 47 & 39 & 51 & & \\
Tarapoto & 51 & 48 & 49 & 45 & 57 & & \\
Gengén & 54 & 50 & 57 & 43 & 57 & \\
Manití & 49 & 47 & 42 & 38 & 44 & 45 & \\
\hline Anuros & 19 & & & & & & \\
San Antonio & 22 & 22 & & & & & \\
Nauta & 7 & 25 & 17 & & & & \\
Ex-Petroleros & 18 & 41 & 21 & 24 & & & \\
Mishana & 27 & 37 & 30 & 28 & 41 & & \\
Tarapoto & 31 & 37 & 35 & 28 & 41 & 52 & \\
Gengén & 27 & 37 & 21 & 16 & 23 & 26 & \\
Manití & & & & & & & \\
Hormigas & 35 & & & & & & \\
San Antonio & 33 & 23 & & & & & \\
Nauta & 21 & 50 & 36 & & & & \\
Ex-Petroleros & 57 & 50 & 38 & 42 & & & \\
Mishana & 43 & 14 & 45 & 25 & 29 & & \\
Tarapoto & 29 & 21 & 44 & 22 & 39 & 28 & \\
Gengén & 35 & 27 & 36 & 50 & 50 & 36 & \\
Manití &
\end{tabular}

Las Figuras 6, 7 y 8 presentan gráficamente los patrones de semejanzas y diferencias faunísticas entre las localidades inventariadas. Si comparamos los patrones en los gráficos basados en presencia/ausencia (6a y 7a) con los que toman en cuenta la abundancia local ( $6 \mathrm{~b}$ y $7 \mathrm{~b}$ ), notamos que hay poca concordancia entre los patrones. Para las aves, la localidad de Ex-Petroleros se mantiene faunísticamente muy diferente a las demás localidades, a pesar de su ubicación geográficamente céntrica (Figura 5), mientras que Andoas, a pesar de su relativa lejanía geográfica (Cuadro 1), mantiene su afinidad faunística con varias localidades de Iquitos. El patrón respectivo de los anuros muestra poca concordancia con las aves: en los anuros las localidades de Nauta y Andoas se mantienen faunísticamente muy diferentes a las demás localidades. Las hormigas muestran un patrón de semejanzas distinto, donde Mishana, San Antonio y Ex-Petroleros son faunísticamente las localidades más diferentes.
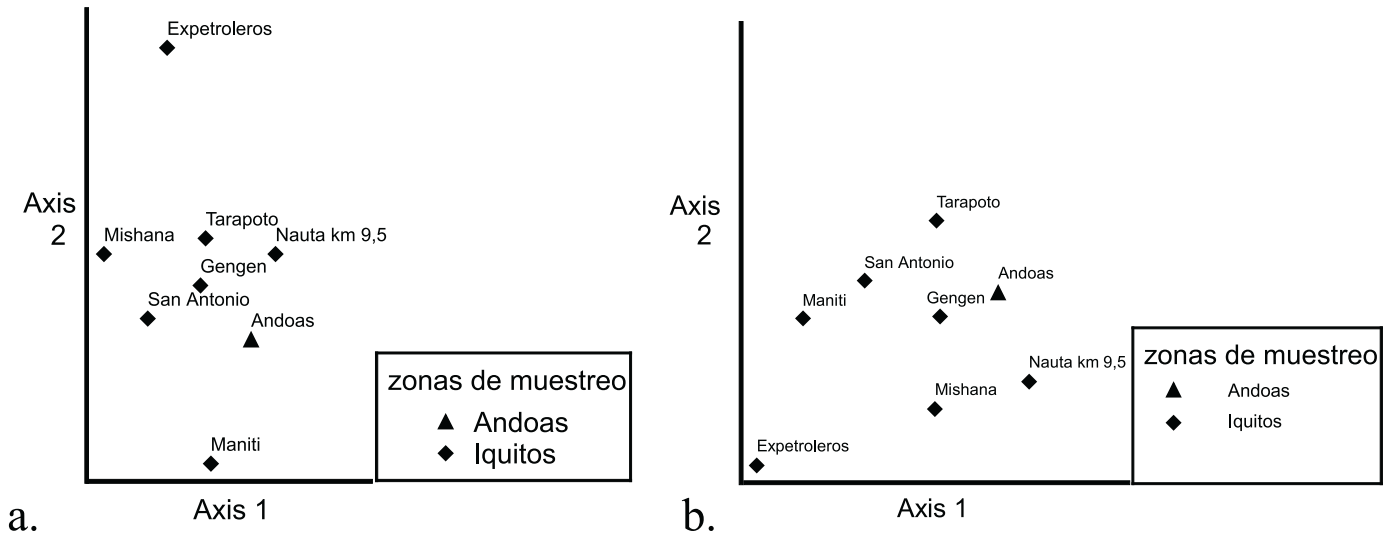

Figura 6. Ordenación por escalarización multidimensional no métrica NMS (Non-Metric Multidimensional Scaling) de la composición de la avifauna (a) basada en el índice de Sørensen (presencia - ausencia) y (b) basada en el índice de Steinhaus (abundancia), en la sub-regiòn de Andoas - Iquitos. 


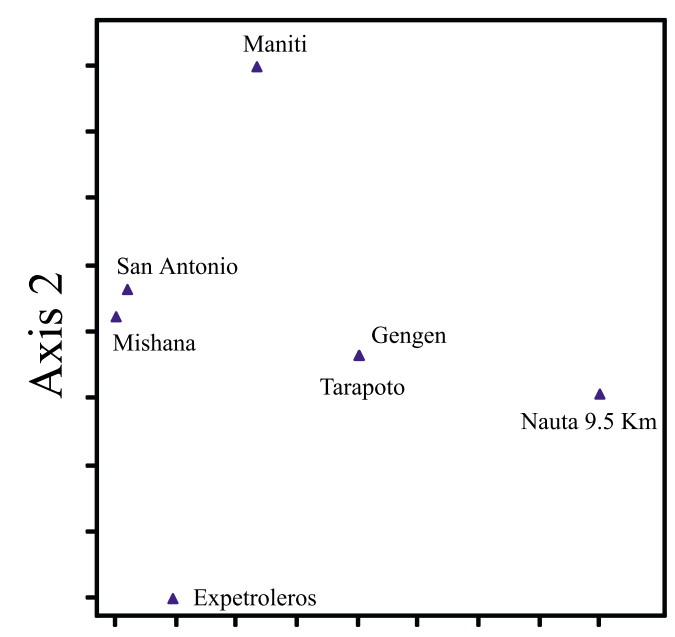

a.

\section{Axis 1}

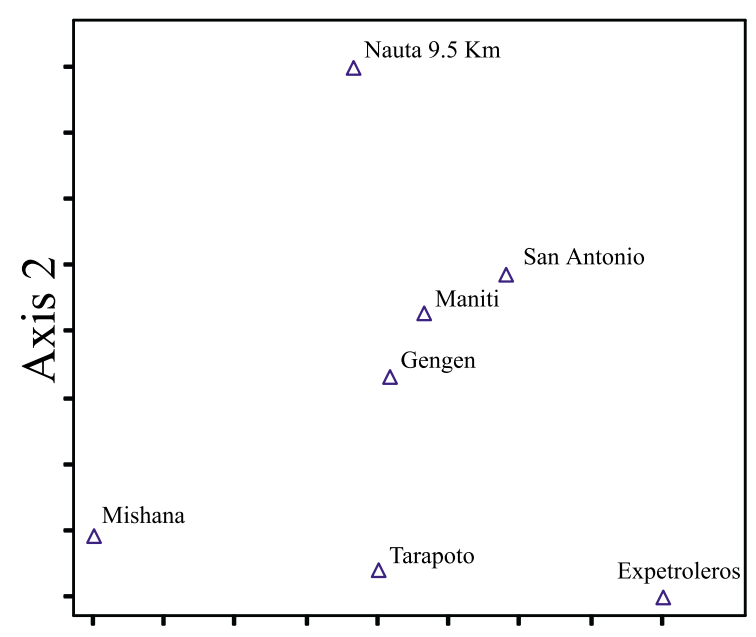

b.

Axis 1

Figura 7. Ordenación por escalarización multidimensional no métrica NMS (Non-Metric Multidimensional Scaling) de la composición faunìstica de los anuros, (a) basada en el índice de Sørensen (presencia - ausencia) y (b) basada en el índice de Steinhaus (abundancia), en la sub-región de Andoas Iquitos.

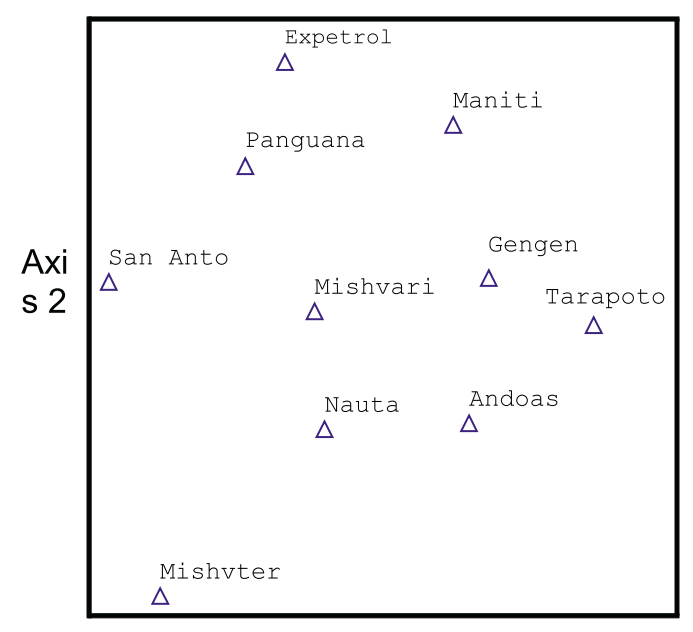

Axis 1

Figura 8. Ordenación por escalarización multidimensional no métrica NMS (Non-Metric Multidimensional Scaling) basada en el índice de Steinhaus de la composición faunística de las hormigas (tribu Dacetini) en la sub-región de Andoas - Iquitos. 


\subsection{Correlaciones entre grupos indicadores, árboles y suelo}

Fueron calculadas las siguientes correlaciones para la zona de Iquitos:

1. Composición faunística de aves con las composiciones correspondientes de árboles, palmeras y hormigas;

2. Composición faunística de anuros con la composición florística de árboles y con las características del suelo, respectivamente;

3. Composición faunística de hormigas con las composiciones correspondientes de árboles, palmeras, anfibios, y con las características del suelo, respectivamente.

4. Composición florística de palmeras con la composición florística de árboles y con las caraterísticas del suelo, respectivamente.

Los resultados indican que no hay correlaciones significativas para ninguno de los grupos faunísticos, pero hay una fuerte correlación entre las palmeras y los árboles (Cuadro 8). A pesar de esta correlación, y del hecho de que los datos de un estudio anterior de los árboles (Ruokolainen y Tuomisto, 1998), muestran una fuerte correlación entre éstos y el suelo $(r=0.67, p=0.003)$, la correlación hallada en el presente estudio entre las palmeras y el suelo resultó relativamente débil (Cuadro 8).

Cuadro 8. Correlaciones entre grupos indicadores, árboles y suelo.

\begin{tabular}{llll}
\hline & Correlación & $\mathbf{p}$ & \\
\hline Aves & Árboles & -0.13 & \\
& Palmeras & -0.12 & \\
Anuros & Hormigas & -0.034 & 0.20 \\
& Árboles & 0.30 & 0.16 \\
Hormigas & Suelo & 0.34 & \\
& Árboles & -0.207 & \\
& Palmeras & -0.273 & \\
Palmeras & Anuros & -0.297 & 0.001 \\
& Suelo & -0.127 & 0.116 \\
\hline
\end{tabular}

\subsection{Correlación entre patrones florísticos y patrones de reflectancia en imágenes de satélite}

La correlación entre la composición florística (basada en el índice de Steinhaus) de los helechos de los transectos de inventario en Andoas y los valores correspondientes de reflectancia muestra la existencia de una correlación positiva entre los helechos y las cuatro bandas de reflectancia en general $(r=0.66, p=0.004)$. Asimismo, la correlación es positiva entre los helechos y cada una de las bandas seleccionadas (Cuadro 9), indicando que los cambios ambientales registrados por la imagen de satélite se reflejan en la composición florística de los helechos. 
Cuadro 9. Correlaciones entre la composición florística de helechos y los valores de reflectancia en imágenes de satélite.

\begin{tabular}{ccc}
\hline Banda de reflectancia & Correlación & $\mathrm{p}$ \\
\hline Banda 3 & 0.33 & 0.078 \\
Banda 4 & 0.69 & 0.003 \\
Banda 5 & 0.69 & 0.004 \\
Banda 7 & 0.58 & 0.017 \\
\hline
\end{tabular}

\section{DISCUSIÓN Y CONCLUSIONES}

\subsection{Riqueza de especies}

El muestreo a nivel macroregional reportó marcadas diferencias en la riqueza de especies entre las zonas muestreadas. Entre las cuatro zonas donde fueron inventariados los tres grupos de plantas indicadoras, los tres grupos mostraron un patrón concordante en que Andoas fue la zona más rica en especies, seguida por Tambopata, y Pampa Hermosa fue la más pobre. También la riqueza de especies únicas (especies registradas sólo en una zona) sigue el mismo patrón concordante, indicando que la mayor riqueza de especies se debe más que nada a la mayor presencia de especies raras, endémicas y/o especialistas de hábitats restringidos. Por ende, la explicación más plausible de la mayor riqueza de Andoas es que esta zona presenta una heterogeneidad edáfica mayor que las otras zonas. La presencia únicamente en esta zona de sedimentos con material de origen volcánico - en concentraciones y combinaciones localmente variables - originaría una diversidad mayor de tipos de suelos y hábitats. Los resultados del análisis en curso de las muestras edáficas permitirán una evaluación más completa del papel de las características edáficas en relación con el patrón de riqueza de especies observado.

En contraste con lo hallado a nivel macroregional, los grupos indicadores inventariados en la sub-región de Andoas - Iquitos (palmeras, aves, anuros y hormigas), no mostraron ningún patrón marcado y concordante (entre especies) de diferencias locales en cuanto a riqueza de especies. Sin embargo, hay que notar que el esfuerzo de inventario aquí fue mucho menor, y probablemente insuficiente para revelar diferencias reales que pudiera haber.

\subsection{Similitudes y diferencias en la composición de especies}

Los análisis de similitudes florísticas y faunísticas entre las zonas muestreadas a nivel macroregional y entre las localidades inventariadas a nivel sub-regional, respectivamente, dieron resultados algo divergentes entre sí cuando se empleó el índice de Sørensen (basado en presencia-ausencia de especies) y cuando se empleó el indice de Steinhaus (basado en abundancia de las especies). Esto también fue el caso en algunos estudios anteriores de palmeras (Vormisto, 2000) y helechos (Tuomisto y Poulsen, 1996) en la región y sus probables causas fueron examinadas por estos autores.

No obstante, tomando en cuenta el conjunto de datos y especies, se observa, a nivel de la macroregión, una comparativamente mayor similitud florística entre Andoas y Tambopata - las zonas geográficamente más distantes entre sí - por un lado, y entre Tambopata e Iñapari - las zonas geográficamente más cercanas entre sí - por otro lado. Es evidente, entonces, que la distancia geográfica entre áreas no es el principal factor determinante de las similitudes y diferencias, por lo menos para los grupos florísticos incluidos en este estudio.

Uno de los motivos principales de este estudio era investigar si los diferentes grupos de flora y fauna forman asociaciones entre sí - es decir, si las diferencias y semejanzas en la composición de especies de diferentes grupos, por ejemplo helechos y aves, entre diferentes lugares reflejan más o menos el mismo patrón. De haber una buena concordancia entre los grupos, uno necesitaría sólo verificar los cambios en la composición de especies en un grupo para predecir los cambios en la composición de especies en los otros grupos. La existencia 
de esta concordancia tendría obvias ventajas para la documentación de los patrones generales de semejanzas y diferencias faunísticas y florísticas en el área de interés.

Los resultados que obtuvimos en la subregión de Andoas - Iquitos nos sugieren que no existe tal asociación entre la flora y fauna de los bosques de tierra firme, o por lo menos que esta asociación no es muy fuerte. Nuestros resultados, en el sentido de que los patrones florísticos de los diferentes grupos de plantas están correlacionados entre sí, y de que este patrón común es muy similar a los patrones que se observan referente a los suelos y en la imágen de satélite, confirman las observaciones semejantes anteriores (Ruokolainen et al., 1997, Ruokolainen \& Tuomisto, 1998, Vormisto et al., 2000). Por tanto, parece que la flora tiene un comportamiento único que, por lo menos en parte, está controlado por la calidad (contenido de nutrientes, textura, etc.) del suelo. Sin embargo, la composición de especies de la fauna -o por lo menos de los grupos inventariados en este estudio-, no parece seguir los patrones de la flora. Sin embargo, hay que recordar que este estudio de correlación entre los grupos de flora y fauna incluyó solo ocho localidades. Este es un número relativamente pequeño y por eso puede ser que una correlación en efecto existe, pero que no fue evidente en una muestra tan reducida. Si hay una correlación entre la flora y la fauna, ésta evidentemente no es tan fuerte como la que ocurre entre los diferentes componentes de la flora, ya que con sólo siete lugares de muestreo fueron registradas correlaciones relativamente altas y estadísticamente significativas entre helechos, melastomatáceas y árboles en la zona de Iquitos (Ruokolainen et al., 1997).

\subsection{Conclusiones}

Los resultados indican que los tres grupos de flora estudiados tienen un comportamiento casi único, pero los grupos de animales no comparten este patrón. Este significa que prácticamente cualquiera de estos grupos de plantas puede servir como indicador de los patrones de distribución de otros grupos de plantas. Además, una parte significativa de la variación florística puede ser observada en las imágenes de satélite, lo que posibilita el uso de estas como una herramienta de apoyo para detectar y mapear áreas importantes para la conservación y el uso de los recursos de la flora. Sin embargo, las plantas no parecen servir como indicadores de patrones de distribución de especies de animales o por lo menos no para los grupos de fauna investigados en el presente estudio.

Nuestras conclusiones referente a esto último son, sin embargo, solo preliminares, ya que el inventario de los grupos de fauna evidentemente no fue suficientemente intensivo ni amplio para revelar posibles patrones faunísticos a un nivel de diferencias ambientales tan fino como en este estudio.

\section{AGRADECIMIENTOS}

Nuestro agradecimiento al proyecto BIODAMAZ, Perú - Finlandia, por la oportunidad de realizar estos estudios.

\section{BIBLIOGRAFÍA}

ALONSO, L.E. 2000. Ants as indicators of diversity. En: Agosti, D.; Majer, J.D.; Alonso, L.E.; Schultz, T.R. (eds.). Ants: Standard Methods for Measuring and Monitoring Biodiversity. Smithsonian Institution Press, Washington y Londres. 280 pp.

BIODAMAZ. 2004. Guía para estudiar patrones de distribución de especies amazónicas. Documento Técnico No 06. Serie BIODAMAZ-IIAP. Iquitos, Perú.

HEYER, W.R.; DONNELLY, M.A.; MCDIARMID, R.W.; HAYEK, L.C.; FOSTER, M.S. 1994. Measuring and Monitoring Biological Diversity. Standard Methods for Amphibians. Smithsonian Institution Press, Washington, D.C. 364 pp. 
LEGENDRE, P. \& LEGENDRE, L. 1998. Numerical Ecology. Second English Edition. Elsevier, Amsterdam.

MAJER, J.D. 1983. Ants: Bioindicators of mine site rehabilitation, land-use, and land conservation. Environmental Management 7 (4): 375-383.

PATTON, J.L.; DA SILVA, M.N.; MALCOLM, J.R. 1994. Gene genealogy and differentiation among arboreal spiny rats (Rodentia: Echinyidae) on the Amazon basin: a test of the riverine barrier hypothesis. Evolution 48: 1314-1323.

RUOKOLAINEN, K.; TUOMISTO, H. 1998. Vegetación natural de la zona de Iquitos. En: Kalliola, R.; Flores Paitán, S. (eds.). Geoecología y desarrollo amazónico: estudio integrado en la zona de Iquitos, Perú. Annales Universitatis Turkuensis Ser. A II 114: 253-365.

RUOKOLAINEN, K.; LINNA, A.; TUOMISTO, H. 1997. Use of Melastomataceae and pteridophytes for revealing phytogeographical patterns in Amazonian rainforests. J. Tropical Ecology 13: 243-256.

RUOKOLAINEN, K.; TUOMISTO, H.; RÍOS, R.; TORRES, A.; GARCÍA, M. 1994. Comparación florística de doce parcelas en bosque de tierra firme en la Amazonia peruana. Acta Amazonica 24: 31-47.

SIAMAZONIA - Sistema de Información de Diversidad Biológica y Ambiental de la Amazonía Peruana. www.siamazonia.org.pe.

TUOMISTO, H.; POULSEN A.D. 1996. Influence of edaphic specialization on pteridophyte distribution in neotropical rain forests. Journal of Biogeography 23: 283-293.

TUOMISTO, H.; RUOKOLAINEN, K. 1998. Uso de especies indicadoras para determinar características del bosque y de la tierra. En: Kalliola, R.; Flores Paitán, S. (eds.). Geoecología y desarrollo amazónico: estudio integrado en la zona de Iquitos, Perú. Annales Universitatis Turkuensis Ser. A II 114: 481-491.

VORMISTO, J. 2000. Palms in the rainforests of Peruvian Amazonia: uses and distribution. Annales Universitatis Turkuensis Ser. A II 138.

VORMISTO, J.; PHILLIPS, O.; RUOKOLAINEN, K.; TUOMISTO, H.; VÁSQUEZ, R. 2000. A comparison of small-scale distribution patterns of four plant groups in an Amazonian rainforest. Ecography 23: 349-359. 
Anexo 1. Listado taxonómico y de abundancia de especies y morfoespecies de palmeras registradas en cinco zonas de muestreo en la selva baja peruana.

\begin{tabular}{|c|c|c|c|c|c|}
\hline ESPECIE & ANDOAS & IQUITOS & $\begin{array}{c}\text { PAMPA } \\
\text { HERMOSA }\end{array}$ & IÑAPARI & TAMBOPATA \\
\hline Aiphanes eggersii & & & 3 & 17 & \\
\hline Aiphanes ulei & 47 & 4 & 3 & & \\
\hline Aphandra natalia & 17 & & & & \\
\hline Astrocaryum chambira & 41 & 32 & & & \\
\hline Astrocaryum gratum & & 29 & & 2 & 38 \\
\hline Astrocaryum macrocalix & & 33 & & 1 & \\
\hline Astrocaryum murumuru & 6 & & & & \\
\hline Astrocaryum sp. & 37 & 51 & & & \\
\hline Astrocaryum sp.I & 26 & & & & \\
\hline Astrocaryum sp.II & 29 & & & & \\
\hline Astrocaryum sp. IV & & & 411 & & \\
\hline \multicolumn{6}{|l|}{ Astrocaryum sp.5 } \\
\hline Attalea butyracea & & & & & 21 \\
\hline Attalea insignis & 3 & 2 & 1 & & 4 \\
\hline Attalea maripa & 13 & 1 & 1 & 9 & 1 \\
\hline \multicolumn{6}{|l|}{ Attalea microcarpa } \\
\hline Attalea phalerata & & & 1342 & & 212 \\
\hline Attalea racemosa & & 21 & & & \\
\hline Attalea tessmanii & & & 128 & & \\
\hline Bactris acanthocarpa & 27 & 37 & & 79 & 79 \\
\hline Bactris acanthocarpoides & 1 & 10 & & & \\
\hline Bactris bifida & & 86 & & & \\
\hline Bactris brongniartii & 11 & 33 & 7 & & 28 \\
\hline Bactris concinna & & & 48 & & \\
\hline Bactris corosila & & 5 & & & \\
\hline Bactris hirta var.hirta & 8 & 27 & & & 29 \\
\hline Bactris hirta var.pulchra & 3 & 24 & & 32 & 51 \\
\hline Bactris gassipaes & & 18 & & 49 & \\
\hline Bactris killipii & & 4 & & & \\
\hline Bactris maraja & 2 & 19 & 2 & 132 & \\
\hline Bactris monticula & & 4 & & & \\
\hline Bactris piranga & & 57 & & & \\
\hline Bactris simplicifrons & 33 & 73 & & 13 & 6 \\
\hline Bactris sphaerocarpa & & 20 & & & 4 \\
\hline Bactris sp.1 & 1 & & & & \\
\hline Bactris sp.2 & & 161 & 151 & 60 & 45 \\
\hline Bactris sp.3 & 10 & 10 & & & \\
\hline Bactris sp.4 & 7 & & & & \\
\hline Bactris sp.5 & & 11 & & 2 & \\
\hline Bactris sp.6 & 23 & & & & \\
\hline Bactris sp.7 & & 8 & & & \\
\hline Bactris sp. 8 & & & & 1 & \\
\hline Bactris sp.9 & & 2 & & & 53 \\
\hline Bactris sp.10 & & & & 169 & 1 \\
\hline Bactris sp.12 & & 5 & 16 & & \\
\hline Bactris sp.13 & 2 & & & 49 & 6 \\
\hline Bactris sp.14 & 6 & & & & 61 \\
\hline Bactris sp.15 & 17 & & & & \\
\hline \multicolumn{6}{|l|}{ Bactris sp.17 } \\
\hline Bactris sp.18 & & 11 & & 26 & 56 \\
\hline
\end{tabular}




\begin{tabular}{|c|c|c|c|c|c|}
\hline \multirow{2}{*}{\multicolumn{6}{|c|}{$\begin{array}{l}\text { Bactris sp. } 19 \\
\text { Bactris sp. } 20\end{array}$}} \\
\hline & & & & & \\
\hline Chamaedora pauciflora & 46 & 4 & & & 21 \\
\hline Chamaedora pinnafrons & 8 & & & & 92 \\
\hline Chelyocarpus repens & & 1 & & & \\
\hline Chelyocarpus ulei & 40 & 4 & & & 11 \\
\hline Desmoncus giganteus & 4 & 2 & & 3 & \\
\hline Desmoncus mitis & 10 & 2 & 6 & & \\
\hline Desmoncus polyacanthos & 6 & 2 & & 21 & \\
\hline Elaeis guineensis & 4 & & & 1 & \\
\hline Euterpe precatoria & 29 & 31 & 30 & 267 & 281 \\
\hline Geonoma arundinacea & & & & 130 & 6 \\
\hline Geonoma aspidifolia & 29 & & & & \\
\hline Geonoma camana & 3 & & & & 16 \\
\hline Geonoma deversa & 71 & 15 & & 1321 & 1490 \\
\hline Geonoma leptospadix & 3 & 104 & & & \\
\hline Geonoma lindeliana & 3 & 10 & & & \\
\hline $\begin{array}{l}\text { Geonoma macrostachys } \\
\text { varacaulis }\end{array}$ & 80 & 119 & 3 & & 27 \\
\hline $\begin{array}{l}\text { Geonoma macrostachys } \\
\text { varmacrostachys }\end{array}$ & 140 & 131 & & 69 & 54 \\
\hline Geonoma macrostachys I & 31 & 161 & & & \\
\hline Geonoma macrostachys II & 32 & 4 & & & \\
\hline Geonoma macrostachys III & 56 & & & & \\
\hline Geonoma maxima var.maxima & 37 & 1 & & & \\
\hline Geonoma maxima var.spixiana & 8 & & & & 28 \\
\hline Geonoma poeppigiana & 121 & 9 & & & \\
\hline Geonoma spixiana & 4 & & & & \\
\hline Geonoma stricta & 148 & 45 & & & \\
\hline Geonoma stricta var.piscicauda & 51 & 15 & & & \\
\hline Geonoma stricta var.stricta & 7 & 68 & & & 15 \\
\hline Geonoma stricta vartrailii & 98 & 378 & & 259 & \\
\hline Geonoma tamandua & 27 & & & & \\
\hline Geonoma triglochin & 15 & 3 & & & \\
\hline Geonoma sp. & & 6 & & & 2 \\
\hline Hyospate elegans & 385 & 144 & 25 & 52 & 71 \\
\hline Iriartea deltoidea & 201 & 1 & & & 241 \\
\hline Iriartella stenocarpa & 12 & 318 & & & \\
\hline Itaya amicorum & & 8 & & & \\
\hline Lepidocaryum tenиe & 264 & 37 & & & \\
\hline Mauritia flexuosa & & 34 & & & 15 \\
\hline Mauritiella aculeata & & 10 & & 4 & \\
\hline Oenocarpus balickii & & 60 & & & \\
\hline Oenocarpus bataua & 1145 & 309 & 36 & 51 & 44 \\
\hline Oenocarpus mapora & 40 & 20 & 31 & 389 & 223 \\
\hline Pholydostachys synanthera & 22 & 64 & 12 & & \\
\hline Phytelephas macrocarpa & & & & & 29 \\
\hline Phytelephas tenuicaulis & 99 & 30 & 555 & & \\
\hline Prestoea schultzeana & 35 & 1 & & & \\
\hline Socratea exorrhiza & 58 & 137 & 3 & 40 & 97 \\
\hline Syagrus sp. & 3 & 1 & & & \\
\hline $\begin{array}{l}\text { Wendlandiella gracilis } \\
\text { var.simplicifrons }\end{array}$ & & & & & \\
\hline Wettinia agusta & 3 & 295 & & & 23 \\
\hline Wettinia drudei & 157 & 29 & & & 3 \\
\hline Wettinia maynensi & 9 & & & & \\
\hline
\end{tabular}


Anexo 2. Listado taxonómico y de abundancia de especies y morfoespecies de la familia Melastomataceae registradas en cuatro zonas de la selva baja peruana.

\begin{tabular}{|c|c|c|c|c|}
\hline ESPECIE & ANDOAS & $\begin{array}{c}\text { PAMPA } \\
\text { HERMOSA }\end{array}$ & IÑ̃PARI & TAMBOРАТА \\
\hline Aciotis cf. aristata & 2 & 0 & 0 & 1 \\
\hline Adelobotrys "aguda" & 5 & 0 & 0 & 0 \\
\hline Adelobotrys boissieriana & 0 & 0 & 0 & 9 \\
\hline Adelobotrys "coriacea" & 21 & 0 & 0 & 0 \\
\hline Adelobotrys "heterofila" & 8 & 0 & 0 & 31 \\
\hline Adelobotrys "k-tessmanii" & 5 & 0 & 0 & 0 \\
\hline Adelobotrys "marginata 1" & 11 & 0 & 0 & 0 \\
\hline Adelobotrys "marginata 2" & 8 & 0 & 0 & 0 \\
\hline Adelobotrys "pegada" & 4 & 0 & 0 & 0 \\
\hline Adelobotrys "recta" & 14 & 0 & 0 & 0 \\
\hline Adelobotrys rotundifolia & 44 & 0 & 0 & 0 \\
\hline Bellucia pentamera & 17 & 1 & 1 & 2 \\
\hline Blakea cf. hirsutissima & 4 & 0 & 0 & 0 \\
\hline Blakea cf. portentosa & 1 & 0 & 0 & 0 \\
\hline Blakea hirsuta & 8 & 0 & 0 & 0 \\
\hline Blakea "larga" & 1 & 0 & 0 & 0 \\
\hline Blakea "muy pubescente" & 2 & 0 & 0 & 0 \\
\hline Blakea portentosa & 2 & 0 & 0 & 0 \\
\hline Blakea "pubescente" & 4 & 0 & 0 & 0 \\
\hline Blakea rosea & 7 & 0 & 0 & 0 \\
\hline Clidemia sp. & 0 & 0 & 0 & 0 \\
\hline Clidemia allardii & 170 & 1 & 0 & 0 \\
\hline Clidemia capitellata & 1 & 0 & 0 & 0 \\
\hline Clidemia demorphica & 53 & 0 & 0 & 0 \\
\hline Clidemia epiphytica epiphytica & 37 & 0 & 0 & 17 \\
\hline Clidemia epiphytica trichocalix & 72 & 0 & 0 & 0 \\
\hline Clidemia heterophylla & 51 & 0 & 0 & 0 \\
\hline Clidemia hirta & 1 & 0 & 0 & 0 \\
\hline Clidemia japurensis & 3 & 0 & 4 & 0 \\
\hline Clidemia juruensis & 108 & 0 & 0 & 0 \\
\hline Clidemia longifolia & 10 & 0 & 0 & 0 \\
\hline Clidemia piperifolia & 15 & 0 & 0 & 0 \\
\hline Clidemia semijuga & 79 & 0 & 0 & 0 \\
\hline Clidemia septuplinervia & 56 & 0 & 0 & 58 \\
\hline Clidemia simpsonii & 32 & 0 & 0 & 0 \\
\hline Graffrenrieda intermedia & 1 & 0 & 0 & 0 \\
\hline Henriettella verrucosa & 26 & 0 & 0 & 0 \\
\hline Henriettella sp. 1 & 0 & 0 & 0 & 8 \\
\hline Henriettella "suave" & 16 & 0 & 0 & 5 \\
\hline Leandra aristigera & 13 & 0 & 0 & 0 \\
\hline Leandra "blancopendula" & 2 & 0 & 0 & 0 \\
\hline Leandra candelabrum & 34 & 0 & 0 & 0 \\
\hline Leandra caquetana & 9 & 0 & 0 & 0 \\
\hline
\end{tabular}




\begin{tabular}{|c|c|c|c|c|}
\hline ESPECIE & ANDOAS & $\begin{array}{c}\text { PAMPA } \\
\text { HERMOSA }\end{array}$ & IÑAPARI & TAMBOPATA \\
\hline Leandra cf. secundiflora & 4 & 0 & 0 & 0 \\
\hline Leandra chaetodon & 1 & 0 & 0 & 0 \\
\hline Leandra dichotoma & 26 & 0 & 0 & 0 \\
\hline Leandra longicoma & 74 & 19 & 29 & 4 \\
\hline Leandra "longicoma 2" & 0 & 0 & 25 & 3 \\
\hline Leandra macdanielli & 29 & 0 & 0 & 1 \\
\hline Leandra "nervosa" & 0 & 0 & 30 & 0 \\
\hline Leandra "rojopendula" & 5 & 0 & 0 & 0 \\
\hline Leandra secunda & 41 & 0 & 0 & 17 \\
\hline Leandra "secunda rizada" & 0 & 0 & 0 & 5 \\
\hline Loreya dentada & 11 & 0 & 0 & 0 \\
\hline Loreya "dentada 2" & 3 & 0 & 0 & 0 \\
\hline Loreya "levantada" & 1 & 0 & 0 & 0 \\
\hline Loreya "levantada peluda" & 0 & 0 & 2 & 1 \\
\hline Loreya shomburbina & 8 & 1 & 0 & 0 \\
\hline Maieta guianensis & 342 & 0 & 0 & 3 \\
\hline Maieta poeppigii & 61 & 0 & 0 & 1 \\
\hline Miconia "3 puberulenta" & 0 & 0 & 0 & 5 \\
\hline Miconia "abierta" & 19 & 0 & 0 & 0 \\
\hline Miconia “abierta 2" & 0 & 0 & 0 & 11 \\
\hline Miconia "abierta 3" & 0 & 0 & 4 & 0 \\
\hline Miconia "abierta 3 pubescente" & 0 & 0 & 3 & 0 \\
\hline Miconia abreviata & 8 & 0 & 0 & 34 \\
\hline Miconia "abreviata 3" & 0 & 0 & 0 & 17 \\
\hline Miconia acutipetala & 2 & 0 & 0 & 0 \\
\hline Miconia "aepicelada" & 1 & 0 & 0 & 1 \\
\hline Miconia affinis & 0 & 0 & 36 & 0 \\
\hline Miconia "alada" & 12 & 0 & 0 & 0 \\
\hline Miconia "alada 2" & 0 & 0 & 0 & 150 \\
\hline Miconia "alada 3" & 6 & 0 & 0 & 0 \\
\hline Miconia ampla & 20 & 0 & 0 & 0 \\
\hline Miconia "apicelada" & 1 & 0 & 0 & 1 \\
\hline Miconia argyrophylla & 11 & 0 & 0 & 0 \\
\hline Miconia “argyrophylla 2" & 0 & 0 & 11 & 18 \\
\hline Miconia "argyrophylla aguda" & 0 & 0 & 0 & 101 \\
\hline $\begin{array}{l}\text { Miconia "argyrophylla blanca- } \\
\text { plinervada" }\end{array}$ & 0 & 0 & 3 & 15 \\
\hline Miconia aulocalix & 0 & 15 & 0 & 0 \\
\hline Miconia aurea & 7 & 0 & 0 & 2 \\
\hline Miconia aureoides & 2 & 0 & 0 & 51 \\
\hline Miconia barbinervis & 13 & 0 & 0 & 0 \\
\hline Miconia "barbinervis 2" & 17 & 0 & 0 & 0 \\
\hline Miconia brachyobotrya & 13 & 0 & 0 & 0 \\
\hline Miconia brillante & 6 & 0 & 0 & 0 \\
\hline Miconia "cadenita" & 2 & 0 & 0 & 0 \\
\hline
\end{tabular}




\begin{tabular}{|c|c|c|c|c|}
\hline ESPECIE & ANDOAS & $\begin{array}{c}\text { PAMPA } \\
\text { HERMOSA }\end{array}$ & IÑAPARI & TAMBOPATA \\
\hline Miconia “cadenita 2” & 0 & 0 & 0 & 1 \\
\hline Miconia calvescens & 0 & 0 & 1 & 20 \\
\hline Miconia carassana & 18 & 0 & 0 & 0 \\
\hline Miconia centrodesma & 30 & 0 & 0 & 0 \\
\hline Miconia "centro rojo" & 185 & 0 & 0 & 0 \\
\hline Miconia cf. subspicata & 120 & 0 & 0 & 0 \\
\hline Miconia crassinervia & 10 & 0 & 0 & 0 \\
\hline Miconia "cuadriferro" & 6 & 0 & 0 & 7 \\
\hline Miconia "cuchara" & 0 & 0 & 0 & 75 \\
\hline Miconia decurrens & 25 & 0 & 0 & 2 \\
\hline Miconia "desepse" & 66 & 0 & 0 & 0 \\
\hline Miconia dispar & 84 & 0 & 0 & 0 \\
\hline Miconia elata & 11 & 0 & 0 & 0 \\
\hline Miconia eleagnoides & 0 & 0 & 0 & 2 \\
\hline Miconia "eleagnoides corta" & 172 & 0 & 0 & 33 \\
\hline Miconia "eleagnoides corta 2" & 0 & 0 & 0 & 1 \\
\hline Miconia "eleagnoides larga" & 41 & 37 & 25 & 7 \\
\hline Miconia "emendata l" & 3 & 0 & 0 & 0 \\
\hline Miconia "emendata 3" & 2 & 0 & 0 & 0 \\
\hline Miconia fosteri & 29 & 0 & 0 & 25 \\
\hline Miconia grandifolia & 21 & 0 & 0 & 1 \\
\hline Miconia "jegensis" & 26 & 0 & 0 & 9 \\
\hline Miconia laevigata & 56 & 0 & 0 & 35 \\
\hline Miconia "laevigata 2" & 17 & 0 & 1 & 9 \\
\hline Miconia lamprofila & 4 & 0 & 8 & 0 \\
\hline Miconia "lengua" & 0 & 0 & 0 & 2 \\
\hline Miconia longifolia & 10 & 2 & 0 & 0 \\
\hline Miconia lourteigiana & 15 & 0 & 0 & 0 \\
\hline Miconia lugonis & 2 & 0 & 0 & 0 \\
\hline Miconia napoana & 3 & 0 & 0 & 0 \\
\hline Miconia "napoana 2” & 0 & 4 & 0 & 7 \\
\hline Miconia "napoana rara" & 1 & 0 & 0 & 0 \\
\hline Miconia nervosa & 118 & 4 & 13 & 25 \\
\hline Miconia "niidea" & 2 & 0 & 0 & 0 \\
\hline Miconia "no bulata" & 105 & 0 & 0 & 0 \\
\hline Miconia "no poeppiggi" & 9 & 3 & 0 & 0 \\
\hline Miconia "obovadorostrada" & 65 & 0 & 0 & 0 \\
\hline Miconia "ovaloalada" & 81 & 0 & 0 & 0 \\
\hline Miconia palaceae & 17 & 0 & 0 & 0 \\
\hline Miconia "patapollo con pelos" & 0 & 0 & 0 & 11 \\
\hline Miconia "peciolo enrollado" & 14 & 0 & 0 & 8 \\
\hline Miconia "peciolo enrollado 2" & 0 & 0 & 0 & 4 \\
\hline $\begin{array}{l}\text { Miconia “ peciolo y tallo } \\
\text { pubescente }\end{array}$ & 0 & 0 & 3 & 0 \\
\hline Miconia "peluda rizada" & 0 & 3 & 0 & 17 \\
\hline
\end{tabular}




\begin{tabular}{|c|c|c|c|c|}
\hline ESPECIE & ANDOAS & $\begin{array}{c}\text { PAMPA } \\
\text { HERMOSA }\end{array}$ & IÑAPARI & TAMBOPATA \\
\hline Miconia "poco nervia" & 3 & 0 & 0 & 0 \\
\hline Miconia prasina & 28 & 0 & 0 & 0 \\
\hline Miconia procumbens & 4 & 0 & 0 & 14 \\
\hline Miconia pterocaulon & 20 & 0 & 0 & 0 \\
\hline Miconia pubescens & 6 & 0 & 0 & 0 \\
\hline Miconia "puntito" & 1 & 0 & 0 & 0 \\
\hline Miconia "punto" & 2 & 0 & 0 & 0 \\
\hline Miconia rugosa & 76 & 0 & 0 & 0 \\
\hline Miconia serrulata & 30 & 8 & 0 & 58 \\
\hline Miconia "serrulata 2" & 2 & 0 & 0 & 0 \\
\hline Miconia "serrulata 3" & 0 & 0 & 3 & 0 \\
\hline Miconia "serrulata copita" & 0 & 1 & 2 & 8 \\
\hline Miconia schunkei & 53 & 0 & 0 & 256 \\
\hline Miconia sparrei & 48 & 0 & 0 & 0 \\
\hline Miconia splendens & 1 & 0 & 0 & 42 \\
\hline Miconia "splendens 2" & 0 & 0 & 0 & 33 \\
\hline Miconia stelligera & 6 & 0 & 0 & 0 \\
\hline Miconia tetrasperma & 6 & 0 & 0 & 0 \\
\hline Miconia tomentosa & 61 & 0 & 0 & 0 \\
\hline Miconia trailli & 4 & 0 & 0 & 0 \\
\hline Miconia "trihierro" & 24 & 0 & 0 & 0 \\
\hline Miconia trinervia & 39 & 0 & 0 & 11 \\
\hline Miconia triplinervia & 3 & 4 & 8 & 112 \\
\hline Miconia "triplinervia 2" & 0 & 0 & 0 & 18 \\
\hline Miconia umbriensis & 151 & 0 & 0 & 0 \\
\hline Miconia urbaniana & 20 & 0 & 0 & \\
\hline Monolena primulaeflora & 43 & 0 & 0 & 0 \\
\hline Ossaea araneifera & 11 & 0 & 0 & 0 \\
\hline Ossaea boliviensis & 99 & 0 & 0 & 0 \\
\hline Ossaea bullifera & 6 & 0 & 0 & 0 \\
\hline Ossaea cucullata & 12 & 0 & 0 & 0 \\
\hline Salpinga secunda & 9 & 0 & 0 & 0 \\
\hline Tococa caquetana & 28 & 0 & 0 & 0 \\
\hline Tococa "cintura" & 0 & 0 & 0 & 23 \\
\hline Tococa guianensis & 23 & 0 & 0 & 1 \\
\hline Tococa stephanotrichia & 45 & 0 & 0 & 29 \\
\hline Tococa ulei & 66 & 0 & 0 & 0 \\
\hline Triolena amazonica & 16 & 0 & 0 & 14 \\
\hline
\end{tabular}


Anexo 3. Listado taxonómico y de abundancia de especies y morfoespecies de helechos terrestres (Pteridophyta), registradas en cuatro zonas de muestreo en la selva baja peruana.

\begin{tabular}{|c|c|c|c|c|}
\hline ESPECIE & ANDOAS & $\begin{array}{c}\text { PAMPA } \\
\text { HERMOSA }\end{array}$ & IÑAPARI & TAMBOPATA \\
\hline Adiantum nerbrineg & 17 & & & \\
\hline Adiantum cayennense Willd. ex Klozsch & 131 & & & 34 \\
\hline Adiantum cf. petiolatum Desv. & & 25 & 28725 & 725 \\
\hline Adiantum cf. poeppigianum (Kuhn) Hieron. & & 6224 & 72 & \\
\hline Adiantum humile Kunze & 1143 & 101 & & 13 \\
\hline Adiantum obliquum Willd. & 58 & & & \\
\hline Adiantum pulverulentum $\mathrm{L}$. & 337 & 996 & 75 & 5 \\
\hline Adiantum sp. & & & 6 & 88 \\
\hline Adiantum terminatum Kunze ex Miq. & 10 & & & \\
\hline Adiantum tetraphyllum Humb. \& Bonpl. ex Willd., s. 1. & 1 & & & \\
\hline Adiantum tomentosum Klotzsch & 224 & & 1 & 382 \\
\hline Arachniodes sp. & & 6 & 4 & \\
\hline Asplenium cf. pearcei Baker & & 5 & & \\
\hline Asplenium cf. serratum L. & & & 12 & 27 \\
\hline Asplenium cirrhatum Rich. ex Willd. & 25 & & & \\
\hline Asplenium pearcei Baker & 14 & & 17 & 42 \\
\hline Asplenium serratum L. & & 1 & & \\
\hline Asplenium sp. & & & 2 & \\
\hline Asplenium sp1 & & 34 & & \\
\hline Asplenium sp2 & & 1 & & \\
\hline Asplenium stuebelianum Hieron & 6 & & & \\
\hline Bolbitis cf. nicotianifolia (Sw.) Alston & 2 & & & \\
\hline Bolbitis lindigii (Mett.) Ching & 156 & & 27 & 274 \\
\hline Bolbitis nicotianifolia (Sw.) Alston & 9 & & 26 & \\
\hline Campyloneurum sp1 & & & 142 & \\
\hline Campyloneurum sp2 & & & 101 & 19 \\
\hline Campyloneurum sp3 & & & 1 & \\
\hline Campyloneurum sp4 & & & 2 & \\
\hline Campyloneurum coarctatum (Kunze) Fée & 33 & & & \\
\hline Campyloneurum fuscosquamatum Lellinger & 3 & & & \\
\hline Campyloneurum phyllitidis (L.) C. Presl & & & & 6 \\
\hline Campyloneurum repens (Aubl.) C. Presl & 15 & & & 11 \\
\hline cf. Asplenium & & & 12 & \\
\hline cf. Diplazium & & & & 16 \\
\hline cf. Saccoloma & & & & 46 \\
\hline cf. Salpichlaena & 2 & & & \\
\hline cf. Tectaria & & & & 7 \\
\hline cf. Thelypteris & & 1 & & \\
\hline cf. Trichomanes & & & & 3 \\
\hline cf. Woodwardia & & & 26 & 7 \\
\hline Cnemidaria cf. ewanii (Alston) R. M. Tryon & 98 & & & \\
\hline Cnemidaria cf. speciosa C. Presl & & 18 & & \\
\hline Cnemidaria speciosa C. Presl & 190 & & & \\
\hline Cyathea cf. macrosora (Baker) Domin & 114 & & & \\
\hline Cyathea lasiosora (Mett. ex Kuhn) Domin & 2 & & & \\
\hline Cyathea sp. & & & 63 & 324 \\
\hline Cyathea sp1 & 529 & & & \\
\hline Cyathea $\mathrm{sp} 2$ & 13 & & & \\
\hline
\end{tabular}




\begin{tabular}{|c|c|c|c|c|}
\hline ESPECIE & ANDOAS & $\begin{array}{c}\text { PAMPA } \\
\text { HERMOSA }\end{array}$ & IÑAPARI & TAMBOPATA \\
\hline Cyathea $\mathrm{sp} 3$ & 35 & & & \\
\hline Cyathea sp4 & 41 & & & \\
\hline Cyclodium meniscioides (Willd.) C. Presl & 789 & & & \\
\hline Cyclodium trianae (Mett.) A. R. Sm. & 312 & & & \\
\hline Cyclopeltis sp. & & 233 & 1 & 17 \\
\hline Danaea acuminata Tuomisto \& R. C. Moran & 22 & & & \\
\hline Danaea cf. elliptica $\mathrm{Sm}$. & 58 & & & \\
\hline Danaeae cf. nodosa (L.) Sm. & 5 & & & \\
\hline Danaea moritziana C. Presl & 46 & & & \\
\hline Danaea oblanceolada Stolze & 75 & & & \\
\hline Danaea cf. oblanceolada o elliptica & 2 & & & \\
\hline Danaea sp. & & & 29 & 84 \\
\hline Danaea ulei $\mathrm{H}$. Christ & 13 & & & \\
\hline Didymochlaena truncatula (Sw.) J. Sm. & 32 & & 1 & 46 \\
\hline Diplazium pinnatifidum Kunze & 23 & & & \\
\hline Diplazium cristatum (Desv.) Alston & 9 & & & \\
\hline Diplazium sp. & & & & 6 \\
\hline Elaphoglossum cf. alipes Mickel & 2 & & & \\
\hline Elaphoglossum flaccidum (Fée) T. Moore & 17 & & & \\
\hline Elaphoglossum raywaense (Jenman) Alston & 5 & & & \\
\hline Hecistopteris pumila (Spreng.) J. Sm. & 1 & & & \\
\hline Hymenophyllum 15 & & & & 5 \\
\hline Hymenophyllum trichomanoides Bosch & 70 & & & \\
\hline Lindsaea cf. taeniata K. U. Kramer & 13 & & & \\
\hline Lindsaea divaricata Klotzsch & 85 & & & \\
\hline Lindsaea guianensis (Aubl.) Dryand. & 10 & & & \\
\hline Lindsaea lancea $(\mathrm{L}$.$) Bedd.$ & 22 & & & 8 \\
\hline Lindsaea menuda & 1 & & & \\
\hline Lindsaea taeniata $\mathrm{K} . \mathrm{U}$. Kramer & 47 & & & \\
\hline Lomagramma guianensis (Aubl.) Ching & 22 & 1 & 72 & 322 \\
\hline Lomariopsis japurensis (Mart.) J. Sm. & 40 & 64 & 19 & \\
\hline Lomariopsis latipinna Stolze & 17 & & & \\
\hline Lomariopsis nigropaleata Holttum & 325 & 38 & 180 & 2798 \\
\hline Lomariopsis prieuriana Fée & 31 & & & \\
\hline Macrothelypteris torresiana (Gaudich.) Ching & 3 & & & \\
\hline Metaxya rostrata(Kunth) C. Presl & 68 & & & 9 \\
\hline Microgramma baldwinii Brade & 1 & & & \\
\hline Microgramma fuscopunctata (Hook.) Vareschi & 49 & & & \\
\hline Microgramma gusano & & & & 2 \\
\hline Microgramma megalophylla (Desv.) de la Sota & 1 & & & \\
\hline Microgramma percussa (Cav.) de la Sota & 3 & & & 46 \\
\hline Microgramma sp. & & & & 14 \\
\hline Microgramma sp1 & & 1 & & \\
\hline Nephrolepis rivularis (Vahl) Mett. ex Krug & 50 & & & 1 \\
\hline Nephrolepis sp. & & 1 & & \\
\hline Phlebodium sp. & & 2 & 1 & 2 \\
\hline Pityrogramma sp. & & 1 & & \\
\hline Polybotrya caudata Kunze & 43 & 25 & 154 & 1606 \\
\hline Polybotrya caudata o crassirhizoma & & & & 80 \\
\hline Polybotrya cf. caudata Kunze & 2 & & & \\
\hline
\end{tabular}




\begin{tabular}{|c|c|c|c|c|}
\hline ESPECIE & ANDOAS & $\begin{array}{c}\text { PAMPA } \\
\text { HERMOSA }\end{array}$ & IÑAPARI & TAMBOPATA \\
\hline Polybotrya crassirhizoma Lellinger & 143 & 1 & & \\
\hline Polypodium dasypleuron Kunze & 4 & & & \\
\hline Polybotrya osmundacea Humb. \& Bonpl. ex Willd. & 191 & & & 44 \\
\hline Polybotrya pubens Mart. & 221 & & & 5 \\
\hline Polypodium aff. fraxinifolium Jacq. & 3 & & & \\
\hline Polypodium sp. & & & & 19 \\
\hline Polytaenium cajenense (Desv.) Benedict & 1 & & & \\
\hline Polytaenium guayanense (Hieron.) Alston & & & & 3 \\
\hline Saccoloma elegans Kaulf. & 15 & & & \\
\hline Saccoloma inaequale (Kunze) Mett. & 57 & & 5 & 30 \\
\hline Schizaea elegans (Vahl) Sm. & 1 & & & \\
\hline Selaginella cf. parkeri (Hook. \& Grev.) Spring & & & 339 & 50 \\
\hline Selaginella chrysoleuca Spring & 4 & & & \\
\hline Selaginella exaltata (Kunze) Spring & 82 & 1 & 131 & \\
\hline Selaginella roja & & & & 193 \\
\hline Selaginella palmiformis Alston ex Crabbe \& Jermy & 26 & & & \\
\hline Selaginella parkeri (Hook. \& Grev.) Spring & 14 & & & \\
\hline Selaginella speciosa A. Braun & 23 & & & \\
\hline Sin ident 3 & & & & 2 \\
\hline Sin ident 1 & & & 7 & \\
\hline Sin ident 2 & & & & 52 \\
\hline Sin ident 4 & & & & 1 \\
\hline Sticherus longipinnatus (Hook.) Ching & 2 & & & \\
\hline Stigmatopteris cf. heterophlebia (Baker) R. C. Moran & 4 & & & \\
\hline Tectaria centro claro & & & & 1105 \\
\hline Tectaria festoneada & & & 17 & \\
\hline Tectaria grande & & & & 23 \\
\hline Tectaria hoja ancha & & & & 30 \\
\hline Tectaria incisa Cav. & & 247 & 95 & 37 \\
\hline Tectaria incisa Cav. f. vivipara (Jenm.) Morton & 8 & & & \\
\hline Tectaria centro oscuro & & & & 70 \\
\hline Tectaria sp. & 32 & & 13 & \\
\hline Thelypteris (Cyclosorus) opulenta (Kanef.) Fosberg & 62 & & & \\
\hline Thelypteris 1000 & & & 4 & \\
\hline \multicolumn{5}{|c|}{ Thelypteris cf. arcana (Maxon \& C. V. Morton) C. V. Morton 5} \\
\hline Thelypteris cf. macrophylla (Kunze) C. V. Morton & 7 & & & \\
\hline Thelypteris macrophylla (Kunze) C. V. Morton & 31 & & & \\
\hline Thelypteris sp. & 76 & & 34 & 249 \\
\hline Thelypteris sp1 & & 165 & & \\
\hline Thelypteris sp3 & & 20 & & \\
\hline Trichomanes ankersii C. Parker ex Hook. \& Grev. & 49 & & & \\
\hline Trichomanes cf. plumosum Kunze & 8 & & & \\
\hline Trichomanes elegans Rich. & 19 & & & 1 \\
\hline Trichomanes pinnatum Hedw. & 261 & & 6 & 51 \\
\hline Trichomanes trollii Bergdolt & 73 & & 1 & 15 \\
\hline Trichomanes tuerckheimii H. Christ & 2 & & & \\
\hline Tripinnada & & 2 & & \\
\hline Triplophyllum dicksonioides (Fée) Holttum & 10 & & & \\
\hline Triplophyllum funestum (Kunze) Holttum & 36 & & 28 & 104 \\
\hline
\end{tabular}


Anexo 4. Listado taxonómico y de abundancia de especies de aves registradas en nueve localidades de la selva baja peruana.

\begin{tabular}{|c|c|c|c|c|c|c|c|c|c|}
\hline Nombre científico & Andoas & $\begin{array}{c}\text { Nauta } \\
\text { Km } 9.5\end{array}$ & Gengen & Mishana & Tarapoto & $\begin{array}{c}\text { San } \\
\text { Antonio }\end{array}$ & Manití & $\begin{array}{c}\text { Ex- } \\
\text { Petroleros } \\
\end{array}$ & Iñapari \\
\hline Tinamus guttatus & 6 & 11 & 18 & 1 & 3 & 8 & 25 & 3 & 4 \\
\hline Tinamus major & & 1 & 2 & & & 1 & & 1 & 1 \\
\hline Crypturellus bartletti & & 5 & 1 & 2 & 5 & & & 1 & 1 \\
\hline Crypturellus cinereus & & 17 & 11 & & 3 & 5 & & & 2 \\
\hline Crypturellus soui & 1 & & 3 & 2 & 1 & & & 1 & 4 \\
\hline Crypturellus undulatus & & & & & & & & 1 & 1 \\
\hline Crypturellus atrocapillus & & & & & & & & & 2 \\
\hline Crypturellus variegates & & & & 1 & & 9 & 4 & 1 & 4 \\
\hline Sarcoramphus papa & & & & & 2 & & & & \\
\hline Harpagus bidentatus & & & & 2 & 1 & & & & \\
\hline Geranospiza caerulescens & & 1 & & & & & & & \\
\hline Leucopternis schistacea & & & 1 & & & & & & \\
\hline Buteo magnirostris & & & 3 & 6 & 1 & 1 & & 1 & \\
\hline Spizaetus tyrannus & & & 5 & 1 & 2 & & & & 1 \\
\hline Daptrius americanus & 7 & 1 & 6 & & 8 & & 25 & & \\
\hline Daptrius ater & 3 & & & & 1 & & & & \\
\hline Herpetotheres cachinnans & 2 & 2 & 6 & & 4 & 1 & 2 & 3 & \\
\hline Micrastur semitorquatus & & & & 1 & 1 & & & 1 & \\
\hline Falco rufigularis & 1 & 1 & 3 & 3 & & & 2 & & \\
\hline Ortalis guttata & & 1 & 2 & & & & 3 & 2 & 7 \\
\hline Penelope jасquаси & 4 & & 2 & 3 & 1 & & 1 & & 6 \\
\hline Aburria pipile & & & 1 & 2 & 1 & & & & 6 \\
\hline Odontophorus gujanensis & 2 & & & & & & & & \\
\hline Odontophorus stellatus & & & & & & & 8 & & \\
\hline Psophia crepitans & 2 & & & & & & & & \\
\hline Psophia leucoptera & & & & & & & & & 4 \\
\hline Columba especiosa & & & & & & & & & 2 \\
\hline Columba plumbea & 35 & 14 & 66 & 1 & 31 & 5 & 6 & 8 & 2 \\
\hline Columba subvinacea & 13 & 1 & 12 & 3 & 3 & 2 & 2 & & \\
\hline Columbina talpacoti & & 3 & & & & & & & \\
\hline Claravis pretiosa & & & & 8 & & & & & \\
\hline Leptotila rufaxilla & & 3 & & & & & & & 1 \\
\hline Geotrygon montana & 3 & 7 & & & & & 1 & & \\
\hline Ara ararauna & & & & & 4 & & & & 4 \\
\hline Ara chloroptera & & & & & & & & & 2 \\
\hline Ara macao & 14 & & & & 2 & & 2 & & 6 \\
\hline Ara manilata & 4 & & 5 & 7 & & 2 & & & 4 \\
\hline Ara couloni & & & & & & & & & 53 \\
\hline Ara severa & 4 & 2 & 8 & 6 & 18 & & 54 & 4 & 28 \\
\hline Aratinga leucophthalmus & & 4 & 1 & 5 & 1 & 4 & & & 23 \\
\hline Aratinga weddellii & 28 & 5 & 7 & 27 & 45 & 68 & 6 & 2 & 17 \\
\hline Pyrrhura melanura & 1 & 6 & & & & & & & \\
\hline Pyrrhura rupicola & & & & & & & & & 3 \\
\hline Pyrrhura picta & & & & & & & 5 & & \\
\hline Brotogeris cyanoptera & 3 & 4 & 7 & & 185 & 9 & 4 & 45 & 155 \\
\hline Pionites leucogaster & & & & & & & & & 15 \\
\hline Pionites melanocephala & 3 & 21 & 28 & 28 & 4 & 31 & 3 & & \\
\hline Pionopsitta barrabandi & & & & & 5 & & 4 & 4 & 4 \\
\hline Pionus menstruus & 13 & 7 & 8 & & 24 & 19 & & 8 & 26 \\
\hline Amazona amazonica & 4 & & 2 & & & & 1 & & \\
\hline Amazona farinosa & 8 & & & & 8 & 28 & 46 & & 32 \\
\hline Amazona ochrocephala & 2 & 1 & & & 4 & & & & 2 \\
\hline Piaya cayana & 12 & 6 & 5 & 8 & 5 & 3 & 1 & 2 & 4 \\
\hline
\end{tabular}




\begin{tabular}{|c|c|c|c|c|c|c|c|c|c|}
\hline Nombre científico & Andoas & $\begin{array}{c}\text { Nauta } \\
\text { Km } 9.5\end{array}$ & Gengen & Mishana & Tarapoto & $\begin{array}{c}\text { San } \\
\text { Antonio }\end{array}$ & Manití & $\begin{array}{c}\text { Ex- } \\
\text { Petroleros }\end{array}$ & Iñapari \\
\hline Dromococcyx phasianellus & & & & & & 3 & & & \\
\hline Glaucidium hardyi & & & & & & & 1 & & 6 \\
\hline Panyptila cayennensis & & & & 4 & & & & & \\
\hline Threnetes leucurus & 3 & & & & & 1 & & & \\
\hline Phaethornis hispidus & & 1 & 1 & 1 & 1 & 3 & & & 1 \\
\hline Phaethornis augusti & & 1 & & & & & & & \\
\hline Phaethornis bourcieri & 2 & 3 & 1 & & & & & & \\
\hline Phaethornis ruber & 2 & & & & 1 & 1 & & 1 & \\
\hline Phaethornis superciliosus & 3 & 5 & 5 & & 2 & 3 & 3 & 1 & \\
\hline Thalurania furcata & 1 & 3 & 1 & 2 & 2 & & 1 & 1 & 3 \\
\hline Pharomacrus pavoninus & 6 & 8 & 1 & 4 & 3 & 5 & 6 & & \\
\hline Trogon collaris & & & & 1 & & & & & 4 \\
\hline Trogon melanurus & 1 & 1 & & 2 & & 3 & 5 & 1 & 29 \\
\hline Trogon violaceus & & & & & & 1 & & & \\
\hline Trogon viridis & 2 & 21 & 26 & 24 & 35 & 21 & 12 & 16 & 8 \\
\hline Electron platyrhynchum & 6 & 4 & & & & 4 & & & 7 \\
\hline Baryphthengus ruficapillus & & 9 & 2 & 2 & & & & & 2 \\
\hline Momotus momota & & & & 1 & & 2 & 1 & & 8 \\
\hline Galbula albirostris & 8 & 3 & 4 & & 1 & 5 & & & \\
\hline Galbula cyanescens & & & & & & & & & 7 \\
\hline Galbula dea & & 7 & 2 & 2 & & & & & 2 \\
\hline Jacamerops aurea & & 4 & 2 & 1 & & 1 & & & \\
\hline Notharchus macrorhynchos & 1 & 2 & 2 & 5 & 2 & 1 & 2 & 1 & 11 \\
\hline Notharchus ordii & & & & 3 & & & & & \\
\hline Bucco macrodactylus & & & & & & 2 & & & \\
\hline Bucco tamatia & & & 1 & & & & & & \\
\hline Nystalus striolatus & & & & & & & 5 & & 2 \\
\hline Malacoptila fusca & & 5 & 3 & & & & & & \\
\hline Nonnula brunnea & & & & & & & 2 & & \\
\hline Monasa morphoeus & 5 & 2 & & 2 & & 4 & & & 7 \\
\hline Monasa nigrifrons & 8 & 8 & 2 & & & 3 & 5 & & 2 \\
\hline Capito niger & 41 & 28 & 41 & 23 & 65 & 34 & 25 & 2 & \\
\hline Capito auratus & & & & & & & & & 21 \\
\hline Eubucco richardsoni & 4 & & & & 4 & & 7 & & 1 \\
\hline Pteroglossus castanotis & 1 & 2 & 7 & & 1 & 15 & & 7 & 3 \\
\hline Pteroglossus mariae & & & & & & & & & 2 \\
\hline Pteroglossus pluricinctus & 6 & & 2 & 1 & & 11 & & & \\
\hline Pteroglossus beauharnaesii & & & & & & & & & 21 \\
\hline Selenidera reinwardtii & 5 & 4 & 2 & 4 & 4 & 1 & 8 & 4 & 6 \\
\hline Ramphastos cuvieri & 36 & 14 & 2 & 6 & 22 & 7 & 15 & 5 & 19 \\
\hline Ramphastos culminatus & 16 & 19 & 26 & 19 & 15 & 5 & 5 & 7 & 12 \\
\hline Melanerpes cruentatus & 18 & 1 & 2 & 3 & 14 & 5 & 2 & 4 & 11 \\
\hline Veniliornis affinis & & & & & & 2 & 2 & & \\
\hline Piculus chrysochloros & 2 & 4 & 3 & 3 & 4 & & 4 & & 4 \\
\hline Piculus flavigula & & & 1 & & & & & & \\
\hline Celeus elegans & 5 & & 1 & & & & & & \\
\hline Celeus flavus & & & & & & & 1 & & \\
\hline Celeus grammicus & 12 & 19 & 23 & 4 & 1 & 6 & 8 & 1 & \\
\hline Celeus torquatus & & & & & & 2 & 1 & & \\
\hline Campephilus melanoleucos & 2 & & 1 & 2 & 5 & 3 & 1 & 2 & 12 \\
\hline Campephilus rubricollis & 6 & 6 & 6 & 2 & 1 & 2 & 2 & 1 & 1 \\
\hline Dendrocincla fuliginosa & & & & & 1 & & & & 1 \\
\hline Dendrocincla merula & & & 1 & 6 & 6 & & & & 1 \\
\hline Deconychura longicauda & & 1 & 1 & 2 & 1 & & & & 2 \\
\hline Sittasomus griseicapillus & 1 & 1 & & & & 1 & & & 7 \\
\hline Glyphorynchus spirurus & 14 & 9 & 14 & 24 & 7 & 3 & 13 & 1 & 6 \\
\hline
\end{tabular}


JUAN JOSÉ RODRÍGUEZ GAMARRA, GLENDA G. CÁRDENAS RAMÍREZ, ALICIA DE LA CRUZ ABARCA, ZAPATA, VÍCTOR HUGO VARGAS PAREDES, PEKKA SOINI Y KALLE RUOKOLAINEN

\begin{tabular}{|c|c|c|c|c|c|c|c|c|c|}
\hline Nombre científico & Andoas & $\begin{array}{c}\text { Nauta } \\
\text { Km } 9.5\end{array}$ & Gengen & Mishana & Tarapoto & $\begin{array}{c}\text { San } \\
\text { Antonio }\end{array}$ & Manití & $\begin{array}{c}\text { Ex- } \\
\text { Petroleros }\end{array}$ & Iñapari \\
\hline Dendrexetastes rufigula & 1 & 1 & 2 & 1 & 1 & 7 & 4 & 1 & 13 \\
\hline $\begin{array}{l}\text { Xiphocolaptes } \\
\text { promeropirhynchus }\end{array}$ & & & & & & & 2 & & \\
\hline Xiphorhynchus guttatus & 16 & 8 & 24 & 7 & 23 & 23 & 16 & 17 & 32 \\
\hline Xiphorhynchus ocellatus & & & & 1 & & & & & \\
\hline Xiphorhynchus spixii & & & & & & & 16 & & 11 \\
\hline $\begin{array}{l}\text { Campylorhamphus } \\
\text { trochilirostris }\end{array}$ & 1 & & & & & & & & \\
\hline Furnarius leucopus & & & & & & & 1 & & \\
\hline Synallaxis rutilans & & & 3 & 1 & 4 & 2 & & & 4 \\
\hline Cranioleuca gutturata & & 1 & & & & & 1 & & \\
\hline Ancistrops strigilatus & & & & & & & 1 & & \\
\hline Hyloctistes subulatus & 1 & 5 & 3 & 4 & 1 & 1 & 16 & 1 & 7 \\
\hline Philydor ruficaudatus & 2 & & & & & & & & 2 \\
\hline Simoxenops ucayalae & & & & & & & & & 5 \\
\hline Automolus ochrolaemus & & 1 & 1 & 2 & & 2 & 1 & & 1 \\
\hline Automolus dorsalis & & 1 & & & & & & & \\
\hline Automolus infuscatus & 9 & 6 & 4 & 2 & 3 & 3 & 4 & & 5 \\
\hline Automolus melanopezus & & & & & & & & & 5 \\
\hline Automolus rubiginosus & & & & & & & & & 1 \\
\hline Automolus rufipileatus & 1 & & & & & & & & \\
\hline Sclerurus caudacutus & & & & & & & & & 1 \\
\hline Cymbilaimus lineatus & 5 & 15 & 7 & 11 & & 7 & 8 & 6 & 16 \\
\hline Frederickena unduligera & & & & & 1 & & & & \\
\hline Thamnophilus aethiops & & & & & 2 & & & & \\
\hline Thamnophilus murinus & 23 & 34 & 32 & 1 & 11 & 2 & 7 & & \\
\hline Thamnophilus schistaceus & 16 & 15 & 19 & 27 & 37 & 26 & 18 & 17 & 21 \\
\hline Pygiptila stellaris & 1 & & & & & 4 & 6 & & 1 \\
\hline Megastictus margaritatus & & 5 & & & & & & & \\
\hline Thamnomanes ardesiacus & 8 & 5 & 5 & 6 & 2 & 14 & 12 & & 5 \\
\hline Thamnomanes schistogynus & & & & & & & & & 23 \\
\hline Thamnomanes caesius & 17 & 33 & 1 & 16 & 12 & 11 & 6 & 1 & \\
\hline Myrmotherula axillaris & 3 & 7 & 7 & 8 & 4 & 19 & 1 & 4 & 15 \\
\hline Myrmotherula longipennis & 5 & 2 & 1 & & & & & & 2 \\
\hline Myrmotherula brachyura & & & & 1 & & 1 & 7 & & 5 \\
\hline Myrmotherula erythrura & 1 & 1 & & & & & & & \\
\hline Myrmotherula haematonota & & 3 & 4 & 7 & 5 & & 1 & & \\
\hline Myrmotherula ornata & & & & & & & 1 & & 4 \\
\hline Myrmotherula hauxwelli & 2 & 1 & 1 & & 2 & 7 & 2 & & \\
\hline Myrmotherula menetriesii & & 5 & 5 & 5 & 1 & 2 & 5 & 1 & 16 \\
\hline Microrhopias quixensis & 1 & & & & & & & & 8 \\
\hline Cercomacra cinerascens & 2 & & 33 & 7 & 3 & 9 & 18 & & 6 \\
\hline Cercomacra nigrescens & 2 & & & & & & & & \\
\hline Cercomacra serva & & & & 1 & & & 3 & & \\
\hline Myrmoborus leucophrys & & & & & 1 & & 1 & & 2 \\
\hline Myrmoborus myotherinus & 11 & & 7 & 1 & 13 & 2 & 12 & 3 & 26 \\
\hline Hypocnemis hypoxantha & 2 & & 1 & 2 & 5 & 3 & 3 & 2 & 2 \\
\hline Hypocnemis cantator & & & 5 & 2 & 3 & 4 & 3 & 2 & 16 \\
\hline Percnostola rufrifrons & & 1 & 1 & 1 & & & & & \\
\hline Percnostola schistacea & & & 1 & & 8 & & 3 & & \\
\hline Percnostola leucostigma & 1 & 1 & 7 & & 6 & & & & \\
\hline Myrmeciza atrothorax & 3 & & & & & & & & \\
\hline Myrmeciza melanoceps & 1 & & & & & & & & \\
\hline Myrmeciza goeldii & & & & & & & & & 1 \\
\hline Myrmeciza fortis & 1 & & 1 & 3 & & & 4 & & \\
\hline Myrmeciza hemimelaena & & & & & & & 9 & & 1 \\
\hline
\end{tabular}




\begin{tabular}{|c|c|c|c|c|c|c|c|c|c|}
\hline Nombre científico & Andoas & $\begin{array}{c}\text { Nauta } \\
\text { Km } 9.5 \\
\end{array}$ & Gengen & Mishana & Tarapoto & $\begin{array}{c}\text { San } \\
\text { Antonio }\end{array}$ & Manití & $\begin{array}{c}\text { Ex- } \\
\text { Petroleros } \\
\end{array}$ & Iñapari \\
\hline Pithys albifrons & 3 & & 1 & 12 & 7 & 5 & 3 & 3 & \\
\hline Gymnopithys leucaspis & & 1 & 4 & 6 & 2 & 1 & 2 & 1 & \\
\hline Gymnopithys salvini & & & & & & & 2 & & 1 \\
\hline Rhegmatorhina melanosticta & 3 & & 1 & 2 & & & 1 & & 3 \\
\hline Hylophylax naevia & 4 & & & 4 & & & 2 & & 1 \\
\hline Hylophylax poecilonota & 7 & 9 & 18 & 7 & 8 & 2 & & 3 & 8 \\
\hline Phlegopsis nigromaculata & & & & & & & & & 4 \\
\hline Phlegopsis erythroptera & 1 & & 2 & 3 & & 3 & & & \\
\hline Formicarius analis & & & 3 & & & & 1 & & 1 \\
\hline Formicarius colma & 3 & & 8 & & & & 3 & & 6 \\
\hline Chamaeza nobilis & & & & & & 2 & & & \\
\hline Hylopezus berlepschi & & & & & & & & & 1 \\
\hline Myrmothera campanisona & 19 & 2 & 16 & & 23 & 8 & 4 & & \\
\hline Conopophaga peruviana & & & & 1 & 1 & 1 & & & \\
\hline Lioseles thoracicus & 16 & 15 & 13 & & 1 & 8 & 8 & 7 & 3 \\
\hline Zimmerius gracilipes & 9 & 7 & 12 & 3 & 6 & 2 & & & \\
\hline Tyrannulus elatus & 3 & 2 & 12 & 5 & 15 & 4 & 7 & & 1 \\
\hline Myiopagis caniceps & & & & & & 1 & 1 & & \\
\hline Myiopagis gaimardii & & & 1 & & & 1 & 1 & & 1 \\
\hline Mionectes oleagineus & 4 & & 1 & & & 4 & 2 & 7 & \\
\hline Mionectes olivaceus & & & & 1 & 1 & & & & \\
\hline Leptopogon amaurocephalus & & & & & & & & & 4 \\
\hline Myiornis ecaudatus & & & & & & & 6 & & 3 \\
\hline Corythopis torquata & & & & 2 & & & & & 6 \\
\hline Poecilotriccus capitale & & & & & 2 & & & & \\
\hline Poecilotriccus albifacies & & & & & & & & & 7 \\
\hline Hemitriccus flammulatus & & & & & & & & & 7 \\
\hline Hemitriccus zosterops & & & & & & & & & 3 \\
\hline Todirostrum chrysocrotaphum & & & 1 & & & & & & 8 \\
\hline Todirostrum maculatum & & & & & 1 & & & & 1 \\
\hline Lophotriccus vitiosus & 3 & 1 & 9 & 12 & 6 & 15 & 21 & 8 & 3 \\
\hline Lophotriccus eulophotes & & & & & & & & & 9 \\
\hline Cnipadectes subbrunneus & 6 & & & & 29 & 5 & 7 & & \\
\hline Ramphotrigon megacephala & & & & & & & & & 1 \\
\hline Ramphotrigon fuscicauda & & & & & & & & & 15 \\
\hline Ramphotrigon ruficauda & & & & & & & 5 & & 8 \\
\hline Rhynchocyclus olivaceus & & & & & & & & & 1 \\
\hline Tolmomyias flaviventris & 4 & 1 & & 3 & 4 & 15 & 2 & & 19 \\
\hline Tolmomyias poliocephalus & 5 & 2 & 6 & 12 & 29 & 14 & 6 & 4 & 2 \\
\hline Platyrinchus coronatus & & & & & & & & & 1 \\
\hline Onychorhynchus coronatus & & & & & & 1 & & & \\
\hline Terenotriccus erythrurus & & & 2 & & & & 2 & & \\
\hline Empidonax euleri & & & & & & & 1 & & 1 \\
\hline Attila bolivianus & 11 & 1 & 1 & 2 & 9 & & 1 & & 3 \\
\hline Attila spadiceus & 3 & 1 & 1 & 8 & 1 & 8 & & 16 & 2 \\
\hline Rhytipterna simplex & & & 3 & 6 & 3 & 8 & 4 & & 12 \\
\hline Laniocera hypopyrra & & & & & & & & & 1 \\
\hline Syristes sibilator & & & & & & & & & 6 \\
\hline Pitangus lictor & & & & & & & & & 1 \\
\hline Megarynchus pitangua & & & & 1 & & & 1 & & \\
\hline Myiodynastes maculatus & & & & 1 & & & & & \\
\hline Legatus leucophaius & & & & & & 3 & 1 & 3 & 1 \\
\hline Tyrannopsis sulphurea & & & & & & & 1 & & \\
\hline Pachyramphus marginatus & 3 & & 8 & 5 & 5 & 3 & & 5 & \\
\hline Pachyramphus polychopterus & 6 & 15 & 19 & 8 & 5 & 11 & 1 & 5 & 3 \\
\hline Platypsaris minor & & & & & 1 & & & & 1 \\
\hline
\end{tabular}


JUAN JOSÉ RODRÍGUEZ GAMARRA, GLENDA G. CÁRDENAS RAMÍREZ, ALICIA DE LA CRUZ ABARCA, ZAPATA, VÍCTOR HUGO VARGAS PAREDES, PEKKA SOINI Y KALLE RUOKOLAINEN

\begin{tabular}{|c|c|c|c|c|c|c|c|c|c|}
\hline Nombre científico & Andoas & $\begin{array}{c}\text { Nauta } \\
\mathrm{Km} 9.5\end{array}$ & Gengen & Mishana & Tarapoto & $\begin{array}{c}\text { San } \\
\text { Antonio }\end{array}$ & Manití & $\begin{array}{c}\text { Ex- } \\
\text { Petroleros }\end{array}$ & Iñapari \\
\hline Schiffornis turdinus & 1 & 8 & 1 & 2 & & & 3 & & \\
\hline Schiffornis major & & 3 & & & 1 & & & & \\
\hline Piprites chloris & 4 & 6 & 5 & 2 & 8 & 4 & 1 & 1 & 6 \\
\hline Tyranneutes stolzmanni & 22 & 36 & & 7 & & 5 & 1 & & \\
\hline Neopelma sulphureiventer & & 1 & & 1 & & & & & \\
\hline Pipra coronota & 41 & 3 & 26 & 15 & 14 & 22 & 23 & 1 & \\
\hline Pipra erithrocephala & 2 & 12 & 1 & 1 & & 4 & 1 & 15 & \\
\hline Pipra fasciicauda & & & & & & & & & 5 \\
\hline Pipra rubrocapilla & & & & & & & 7 & & \\
\hline Pipra chloromeros & & & & & & & & & 5 \\
\hline Pipra pipra & 6 & 3 & 3 & 7 & 3 & & 1 & & \\
\hline Chiroxiphia pareola & 5 & & & & 7 & & 1 & 3 & \\
\hline Machaeropterus regulus & & & & & & & 1 & & \\
\hline Lipaugus vociferans & 25 & 3 & 32 & 7 & 12 & 13 & 19 & & 18 \\
\hline Xipholena punicea & & & & 1 & & & & & \\
\hline Conioptilon mcilhennyi & & & & & & & & & 4 \\
\hline Querula purpurata & 4 & 19 & 13 & 2 & 14 & & 8 & 8 & 8 \\
\hline Campylorhynchus turdinus & & & & & & & & & 1 \\
\hline Thryothorus genibarbis & & & & & & & & & 24 \\
\hline Thryothorus coraya & & & & & 8 & & 1 & 1 & \\
\hline Thryothorus leucotis & 4 & 12 & 1 & & 1 & 19 & 2 & 2 & \\
\hline Henicorhina leucosticta & 2 & & & & & & & & \\
\hline Microcerculus marginatus & 6 & 6 & 1 & 3 & 1 & 5 & 3 & 8 & 7 \\
\hline Cyphorhinus arada & & & & & & 1 & & & 1 \\
\hline Turdus albicollis & 1 & & & & & & & & \\
\hline Turdus hauxwelli & 3 & 6 & & & & 5 & & & 2 \\
\hline Turdus lawrencii & & & & & & 2 & & & 1 \\
\hline Sporophila lineola & & 1 & & & & & & & \\
\hline Sporophila schistacea & & 1 & & & & & & & \\
\hline Pytilus grossus & 3 & & & & 4 & 3 & & & 1 \\
\hline Saltator coerulescens & & & 5 & & & & & & \\
\hline Saltator maximus & 8 & & 1 & & & & & & \\
\hline Cyanocompsa cyanoides & 6 & 1 & & & 1 & & 1 & & 4 \\
\hline Lanio versicolor & & & & & & & & & 1 \\
\hline Tachyphonus cristatus & & & & & & & & & 1 \\
\hline Tachyphonus luctuosus & 1 & & & 1 & & 1 & & & 2 \\
\hline Tachyphonus surinamus & & & & 2 & & 1 & & & \\
\hline Habia rubica & & & & & 1 & & & & \\
\hline Euphonia chrysopasta & 7 & 7 & 1 & 1 & 13 & 2 & 1 & & 2 \\
\hline Euphonia laniirostris & & & & & & 1 & & & \\
\hline Euphonia minuta & & & & & & 3 & 4 & & \\
\hline Euphonia rufiventris & 6 & 4 & & 4 & 8 & 3 & 11 & & 5 \\
\hline Euphonia xanthogaster & 6 & 2 & 2 & 4 & 3 & 2 & & & 3 \\
\hline Tangara chilensis & 37 & 25 & 55 & 45 & 6 & 55 & 25 & 2 & 5 \\
\hline Tangara schrankii & & & & & & & & & 1 \\
\hline Dacnis cayana & & & & & & & & & 1 \\
\hline Dacnis lineata & & & & & & & & & 1 \\
\hline Basileuterus fulvicauda & & & & & & 2 & 2 & & \\
\hline Hylophilus hypoxanthus & 12 & 4 & 12 & 12 & 8 & 7 & 5 & & 12 \\
\hline Icterus cayanensis & & & & 1 & & & & & 1 \\
\hline Psarocolius angustifrons & 1 & 2 & & 1 & & 19 & 1 & 1 & 4 \\
\hline Psarocolius decumanus & & 1 & & & & 5 & & 12 & 1 \\
\hline Psarocolius bifaciatus & & & & & & 4 & 4 & & 3 \\
\hline Cacicus cela & 3 & 1 & & 12 & 6 & 14 & 2 & 13 & 9 \\
\hline Cyanocorax violaceus & 3 & & & & & & & & 9 \\
\hline TOTAL DE ESPECIES & 123 & 109 & 116 & 112 & 113 & 115 & 128 & 67 & 160 \\
\hline
\end{tabular}


Anexo 5. Listado taxonómico y de abundancia de especies de anuros de las familias Dendrobatidae, Hylidae y Leptodactylidae registradas en ocho localidades de la sub-región de Andoas - Iquitos.

\begin{tabular}{|c|c|c|c|c|c|c|c|c|}
\hline Especie & Andoas 1 & $\begin{array}{c}\text { Nauta } \\
\text { Km 9.5 }\end{array}$ & Gengen & Mishana & Tarapoto & $\begin{array}{c}\text { San } \\
\text { Antonio }\end{array}$ & Manití & $\begin{array}{c}\text { Ex- } \\
\text { Petroleros }\end{array}$ \\
\hline \multicolumn{9}{|l|}{ DENDROBATIDAE } \\
\hline Colostethus gr. Trilineatus & 3 & & & & & & 1 & \\
\hline Colostethus cf. marchesianus & & & & & & 2 & 2 & 5 \\
\hline Dendrobates duellmani & & & & & & & 5 & \\
\hline Dendrobates sp. & 5 & 7 & 5 & & & & & \\
\hline Dendrobates reticulatus & & & & 21 & & & & 5 \\
\hline Dendrobates sp. 1 & & & & & 13 & & & \\
\hline Dendrobates ventrimaculatus & & & 2 & & 3 & & & 3 \\
\hline Epipedobates femoralis & & & 7 & 11 & 4 & 1 & 5 & 5 \\
\hline Epipedobates hahneli & & & 2 & & 3 & & & 7 \\
\hline Epipedobates sp. 1 & 1 & & & & & & & \\
\hline Epipedobates zaparo & 1 & & & & & & & \\
\hline \multicolumn{9}{|l|}{ HYLIDAE } \\
\hline Hemiphractus scutatus & & & & & & & 1 & \\
\hline Hemiphractus proboscideus & & & & & & 1 & & \\
\hline Hyla fasciata & & & & & & & & 3 \\
\hline Hyla geographica & & 2 & & & & & & \\
\hline Hyla lanciformis & & 3 & & & & & & \\
\hline Hyla punctata & & & & 1 & & & & \\
\hline Osteocephalus cabrerai & & & 1 & & 1 & & & 2 \\
\hline Osteocephalus planiceps & 1 & 4 & 5 & 2 & 3 & 3 & 3 & \\
\hline Osteocephalus sp. " $2 a ”$ & & & 1 & 2 & & 1 & & 2 \\
\hline Osteocephalus sp. " $2 b "$ & & & & & & & 1 & \\
\hline Osteocephalus taurinus & & 1 & & & & & & 1 \\
\hline Phyllomedusa vaillanti & & & & & & 2 & 1 & \\
\hline Scinax garbei & & & & & & & & 2 \\
\hline Scinax rubra & & & & & & & & 1 \\
\hline \multicolumn{9}{|l|}{ LEPTODACTYLIDAE } \\
\hline Adelophryne sp. $2 b$ & & & & 5 & & & & \\
\hline Adenomera cf. andreae & & 4 & 3 & 5 & 31 & 4 & 7 & 2 \\
\hline Eleutherodactylus carvalhoi & 7 & & 4 & 3 & 2 & 4 & 8 & 2 \\
\hline Eleutherodactylus conspicillatus & 2 & & 1 & 33 & 2 & 1 & 2 & \\
\hline Eleutherodactylus cf. delius & 2 & & & & & & 2 & \\
\hline Eleutherodactylus diadematus & 1 & & & & & & & \\
\hline Eleutherodactylus lacrimosus & & & & 1 & & & & \\
\hline Eleutherodactylus lanthanites & 3 & 5 & 1 & 1 & 1 & & & \\
\hline Eleutherodactylus martiae & & & & 1 & 1 & & & \\
\hline Eleutherodactylus malkini & & 2 & 1 & & 7 & 1 & & \\
\hline Eleutherdactylus ockendeni & 3 & 1 & 1 & 3 & 3 & 1 & 2 & \\
\hline Eleutherodacylus peruvianus & 11 & & & & 1 & 3 & 2 & \\
\hline Eleutherodactylus sp. “1”(5) & & & & & 2 & & & \\
\hline Eleutherodactylus sp. “2”(6) & & & & & & & 2 & \\
\hline Eleutherodactylus sp. “3”(7) & & & & & & & 1 & \\
\hline Eleutherodactylus sp. E & & & 1 & & & & & \\
\hline Eleutherodactylus sp. F & 24 & & & & & & & \\
\hline Eleutherodactylus sp. $H$ & 52 & & & & & & & \\
\hline Eleutherodactylus sp. G & 2 & & 5 & & 1 & & & \\
\hline Eleutherodactylus sp. J & & & 9 & & & & & \\
\hline Eleutherodactylus sp. $K$ & & & 1 & & & & & \\
\hline Eleutherodactylus sp. $L$ & & & & & 1 & & & \\
\hline Eleutherodactylus sulcatus & 1 & 1 & 6 & & 3 & & 1 & 3 \\
\hline Eleutherodactylus ventrimarmoratus & & & & & & 1 & & \\
\hline Ischnocnema quixensis & & 7 & 2 & 4 & 3 & 2 & & 1 \\
\hline Leptodactylus leptodactyloides & & 1 & & & 1 & & & \\
\hline Leptodactylus pentadactylus & & & & & & & 1 & \\
\hline Leptodactylus rhodomyxtas & & & & & & & 1 & \\
\hline Leptodactylus stenodema & & & 1 & 1 & 1 & & 1 & \\
\hline Phyllonastes myrmecoides & & & 3 & 10 & 4 & 1 & & \\
\hline Physalaemus petersi & & 1 & 1 & & & & 1 & \\
\hline Vanzolinius discodactylus & & & & & & & 1 & \\
\hline
\end{tabular}


Anexo 6. Listado taxonómico y de abundancia de especies y morfoespecies de hormigas de la tribu Dacetini registradas en diez localidades de la sub-región de Andoas - Iquitos.

\begin{tabular}{|c|c|c|c|c|c|c|c|c|c|c|}
\hline Especie & Andoas & Nauta & Gengen & Tarapoto & $\begin{array}{l}\text { Mishana } \\
\text { I }\end{array}$ & $\begin{array}{c}\text { Mishana } \\
\text { III }\end{array}$ & $\begin{array}{c}\text { Ex- } \\
\text { Petroleros }\end{array}$ & $\begin{array}{c}\text { San } \\
\text { Antonio }\end{array}$ & Panguana & Manití \\
\hline P. appretiata & 0 & 1 & 1 & 0 & 0 & 0 & 0 & 0 & 0 & 0 \\
\hline P. beebei & 0 & 2 & 0 & 0 & 0 & 0 & 0 & 0 & 0 & 0 \\
\hline P. decipula & 0 & 1 & 222 & 9 & 16 & 0 & 22 & 0 & 19 & 43 \\
\hline P. denticulata & 214 & 41 & 213 & 45 & 67 & 28 & 492 & 98 & 29 & 250 \\
\hline P. eggersi & 2 & 0 & 0 & 0 & 1 & 0 & 1 & 7 & 0 & 2 \\
\hline P. grytava & 0 & 0 & 0 & 0 & 0 & 3 & 0 & 0 & 0 & 0 \\
\hline P. gudlachi & 2 & 0 & 0 & 9 & 0 & 0 & 0 & 0 & 0 & 0 \\
\hline $\begin{array}{l}\text { P. ND } \\
\text { (appretiata } \\
\text { group) }\end{array}$ & 0 & 0 & 1 & 0 & 1 & 0 & 0 & 0 & 0 & 0 \\
\hline P. pholidota & 0 & 0 & 1 & 0 & 0 & 3 & 0 & 0 & 0 & 1 \\
\hline P. reticeps & 0 & 0 & 0 & 0 & 0 & 0 & 1 & 2 & 0 & 0 \\
\hline P. schulzi & 0 & 0 & 0 & 0 & 0 & 0 & 93 & 0 & 0 & 14 \\
\hline P. spl & 0 & 0 & 0 & 0 & 0 & 0 & 0 & 0 & 1 & 0 \\
\hline P. $s p 2$ & 1 & 0 & 0 & 0 & 0 & 0 & 0 & 0 & 0 & 0 \\
\hline P. $s p 3$ & 0 & 0 & 1 & 0 & 0 & 0 & 0 & 0 & 0 & 0 \\
\hline P. sp4 & 0 & 0 & 1 & 0 & 0 & 0 & 0 & 0 & 0 & 0 \\
\hline P. $s p 5$ & 0 & 0 & 0 & 0 & 0 & 0 & 0 & 0 & 1 & 0 \\
\hline P. sp6 & 0 & 0 & 0 & 0 & 0 & 0 & 0 & 0 & 0 & 1 \\
\hline P. subedentata & 35 & 9 & 3 & 7 & 1 & 2 & 0 & 0 & 0 & 24 \\
\hline P. urrhobia & 5 & 1 & 82 & 6 & 0 & 0 & 0 & 0 & 0 & 0 \\
\hline P. villersi & 0 & 0 & 0 & 1 & 0 & 0 & 0 & 0 & 0 & 0 \\
\hline P. zeteki & 1 & 0 & 0 & 6 & 1 & 0 & 0 & 0 & 0 & 40 \\
\hline S. cordovensis & 0 & 0 & 1 & 0 & 0 & 0 & 0 & 0 & 0 & 0 \\
\hline S. elongata & 23 & 9 & 4 & 0 & 2 & 4 & 7 & 7 & 16 & 44 \\
\hline S. incuba & 1 & 0 & 0 & 0 & 0 & 0 & 0 & 1 & 0 & 0 \\
\hline S. monstra & 0 & 0 & 0 & 0 & 0 & 0 & 0 & 0 & 0 & 1 \\
\hline S. perparva & 3 & 3 & 2 & 9 & 1 & 0 & 76 & 10 & 35 & 40 \\
\hline S. precava & 8 & 0 & 0 & 0 & 1 & 0 & 0 & 8 & 0 & 0 \\
\hline S. sp2 & 0 & 0 & 1 & 0 & 0 & 0 & 0 & 0 & 0 & 0 \\
\hline S. sphatula & 0 & 0 & 0 & 0 & 0 & 0 & 0 & 0 & 1 & 0 \\
\hline S. trudifera & 17 & 0 & 2 & 0 & 1 & 2 & 0 & 1 & 3 & 0 \\
\hline
\end{tabular}

